\title{
Communications Technology for Unattended Sensors
}

\author{
David A. Fuess \\ David W. Myers \\ David M. Benzel \\ John Baker
}

August, 1993

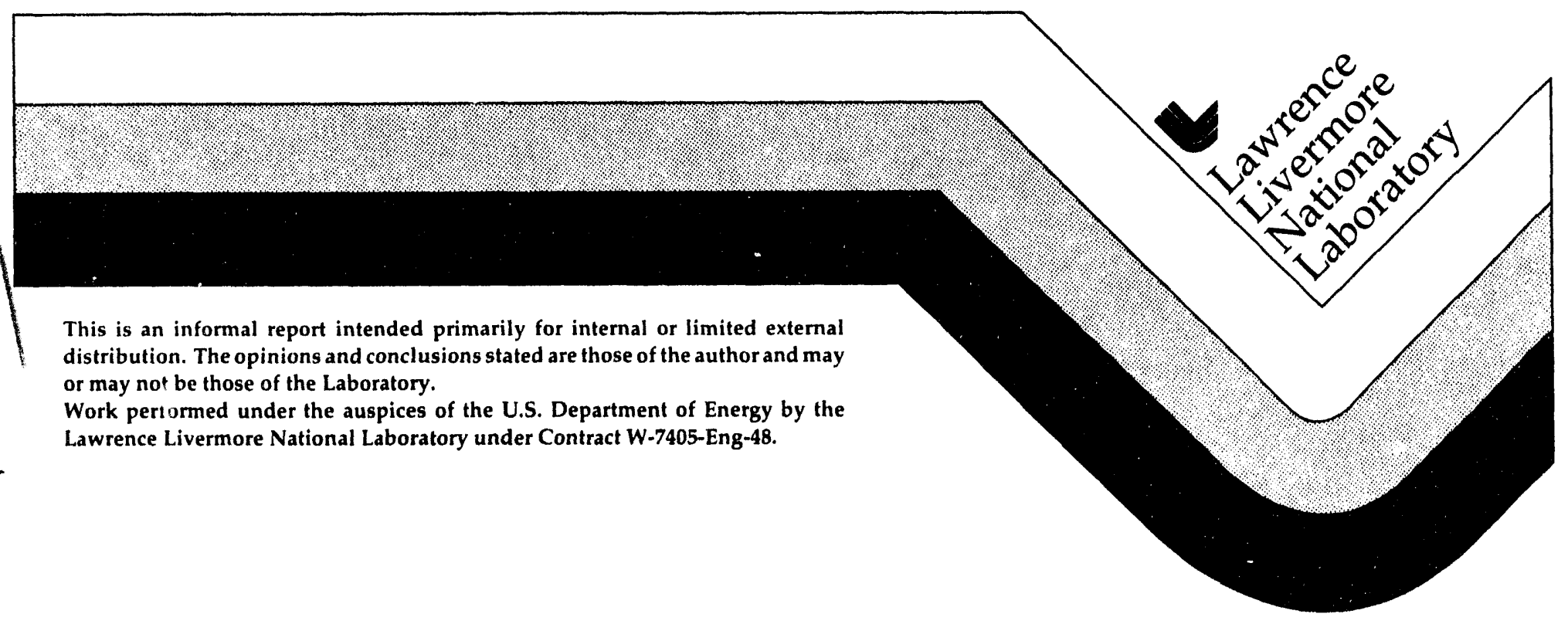




\section{DISCLAIMER}

This document was prepared as an account of work sponsored by an agency of the United States Government. Neither the United States Government nor the University of California nor any of their employees, makes any warranty, express or implied, or assumes any legal liability or responsibility for the accuracy, completeness, or usefulness of any information, apparatus, product, or process disclosed, or represents that its use would not infringe privately own rights. Reference herein to any specific commercial products, process, or service by trade name, trademark, manufacturer, or otherwise, does not necessarily constitute or imply its endorsement, recommendation, or favoring by the United States Government or the University of California. The views and opinions of authors expressed herein do not necessarily state or reflect those of the United States Government or the University of California, and shall not be used for advertising or product endorsement purposes.

This report has been reproduced directly from the best available copy.

Available to DOE and DOE contractors from the Office of Scientific and Technical Information

P.O. Box 62, Oak Ridge, TN 37831

Prices available from (615) 576-8401, FTS 626-8401

Available to the public from the National Technical Information Service

U.S. Department of Commerce 5285 Port Royal Rd., Springfield, VA 22161

Work performed under the auspices of the U.S. Department of Energy by Lawrence Livermore National Laboratory under Contract W-7405-Eng-48. 
UCRL-ID-1 14079

\title{
Communications Technology for Unattended Sensors
}

\author{
David A. Fuess \\ David W. Myers \\ David M. Benzel \\ John Baker
}

Center for Electrical Engineering and Computer Science

Applied Technology Program (J Division)

Nonproliferation, Arms Controls, and International Security Directorate

August, 1993

Lawrence Livermore National Laboratory

Livermore, CA 94551 


\section{Contents}

List of Figures

List of Tables

Abstract

Introduction

Remote Sensor Unit's Exciter/Transmitters Exciter/Transmitter Design

Power Amplifier

Command Receiver

Appendices

Appendix A. Diagrams and Photographs

Appendix B. Power amplifier test data 


\section{List of Figuires}

1. Block diagram of a conceptual miniature synthesized exciter/transmitter.

2. Block diagram of the DSI miniature synthesized exciter/transmitter.

3. Photograph of the DSI miniature synthesized exciter/transmitter.

4. Diagram of a conceptual power amplifier.

5. Photograph of the LCF power amplifier.

6. Diagram of the proof-of-concept command receiver.

7. Photograph of the proof-of-concept command receiver.

Appendix A. Diagrams and Photos

A-1. Diagram of the DSI miniature synthesized exciter/

transmitter loop block diagram.

A-2. Synthesizer-loop block diagram.

A-3. Output power as a function of frequency at $+250 \mathrm{C}$.

A-4. Output power as a function of frequency at $+5000 \mathrm{C}$.

A-5. Output power as a function of frequency at $-30 \infty \mathrm{C}$.

A-6. Supply current as a function of frequency at $+25 \infty \mathrm{C}$.

A-7. Supply current as a function of frequency at $+5000 \mathrm{C}$.

A-8. Supply current as a function of frequency at $-30 \infty \mathrm{C}$.

A-9. Phase noise spectrum, $100 \mathrm{kHz}$ about $400 \mathrm{MHz}$ at $+500^{\circ}$.

A-10. Phase noise spectrum, $100 \mathrm{kHz}$ about $400 \mathrm{MHz}$ at $-3000 \mathrm{C}$.

A-11. Modulation amplitude control gain for constant $25-\mathrm{kHz}$ frequency deviation.

A-12. Demodulated exciter/transmitter output, $40 \mathrm{~Hz}$ modulation, $225 \mathrm{MHz}$ center frequency.

A-13. Demodulated exciter/transmitter output, $40 \mathrm{~Hz}$ modulation, $250 \mathrm{MHz}$ center frequency

A-14. Demodulated exciter/transmitter output, $40 \mathrm{~Hz}$ modulation, $300 \mathrm{MHz}$ center frequency.

A-15. Demodulated exciter/transmitter output, $40 \mathrm{~Hz}$ modulation, $301 \mathrm{MHz}$ center frequency.

A-16. Demodulated exciter/transmitter output, $40 \mathrm{~Hz}$ modulation, $350 \mathrm{MHz}$ center frequency.

A-17. Demodulated exciter/transmitter output, $40 \mathrm{~Hz}$ modulation, $400 \mathrm{~Hz}$ modulation, center frequency.

A-18. Synthesizer programming sequence.

A-19. Block diagram of MISS bus communication interface.

A-20. Photograph of the MISS bus communication interface.

A-21. Photograph of the MISS bus communication breadboard

\section{List of Tables}

1. Specifications for miniature synthesized exciter/transmitter

(as provided to vendor as part of purchase order).

2. Specifications for the LCF power amplifier (purchased item).

3. Command receiver specifications. 


\begin{abstract}
Our objective was designing and demonstrating proof-of-concept communication subsystems for use in unattended sensors. These designs investigated current, advanced technology for frequency synthesis and control, and the use of commercial, highly integrated radio frequency components. The three following subsystems were evaluated: (1) a synthesized (225-400 MHz) exciter/transmitter, (2) a wideband, 100-W, radio-frequency power amplifier (for boosting the level of the exciter/transmitter output), and (3) and a command receiver operating in the 240$270-\mathrm{MHz}$ satellite communication band. These subsystems were integrated into a prototype sensor system. Software was written using the Lawrence Livermore National Laboratory's Modular Intelligent Sensor System (MISS) specification for microprocessor control of these communication elements. Operation of the sensor system using these subsystems was demonstrated.
\end{abstract}




\section{Introduction}

Our objective was designing and demonstrating proof-of-concept (POC) communication subsystems for use in unattended sensors. These designs demonstrated the use of both advanced technology for frequency synthesis and control, and highly integrated commercial radio-frequency (rf) components. Three subsystems were designed and fabricated. Software enhancements were written and appended to existing control software to demonstrate an advanced, prototype sensor system.

The first step in this effort was generating a suitable set of specifications. The primary rationale for these specifications is that they represent nominal ranges of parameters useful in unattended-sensor designs. Secondary objectives included demonstrating a capability for future needs and attaining the packaging volumes.

The subsystems selected for development included an exciter/transmitter, a medium-power amplifier, and a command receiver. The exciter/transmitter provides a synthesized rf signal source that can be FSK-modulated. The frequency range is $225-400 \mathrm{MHz}$ with frequency selection in 5-kHz increments. The power amplifier boosts the level of this rf signal to $100 \mathrm{~W}$. The command receiver operates in the $240-270-\mathrm{MHz}$ satellite communication band.

\section{Remote Sensor Unit's Exciter/Transmitter Design}

The design of the poc exciter/transmitter incorporated a number of innovations. A number of design concepts were evident in generating the specifications. These include-frequency synthesis for carrier frequency generation; linear FM (FSK with binary data) with a signal bandwidth of $25 \mathrm{kHz}$; digitally programmable; synthesizer output port for a receiver local oscillator. Figure 1 is a block diagram of a concept exciter/transmitter; the initial specifications are given in Table 1.

A contract was placed with DSI* for the design of a synthesized exciter/transmitter conforming to these specifications. The block diagram of the DSI transmitter and a photograph of the physical unit are shown in Figs. 2 and 3. The unit generally conforms to the specifications (the exception being the power requirement at high temperature). Supporting technical data are provided in Appendix A.

*Defense Systems, Inc., 1521 Westbranch Drive, McLean, VA 201021 


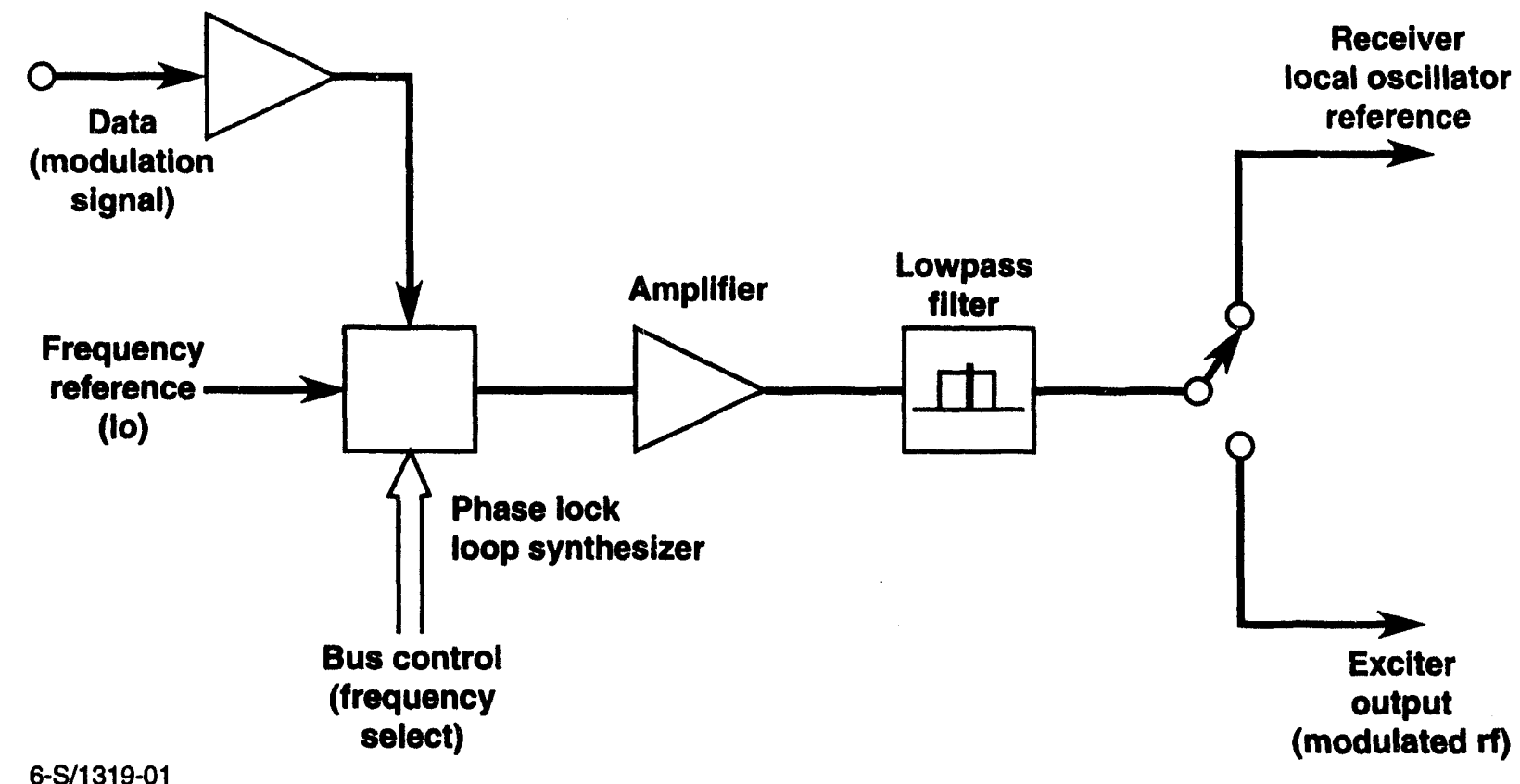

Figure 1. Block diagram of a conceptual miniature synthesized exciter/transmitter. 
Table 1. Specifications for nimiature synthesized exciter/transmitter (as provided to vendor as part of purchase order).

$\begin{array}{ll}\text { frequency } & 225-400 \mathrm{MHz} \\ \text { frequency step size } & 5 \mathrm{kHz} \\ \text { frequency switching speed } & 10 \mathrm{~ms} \text { nominal } \\ \text { frequency stability } & \pm 1 \mathrm{ppm} \text { over temperature } \\ \text { aging rate } & <1 \mathrm{ppm} / \text { year for } 2 \text { years } \\ \text { synthesizer control } & \text { TTL levels } \\ \text { synthesizer output power level } & 10 \mathrm{dBm} \\ \text { modulation } & \mathrm{FSK}, 25-\mathrm{kHz} \text { wide, nominal } \\ \text { date rate } & 2400-9600 \mathrm{baud} \\ \text { data format } & \mathrm{TTL} \text { levels } \\ \text { power output } & 0.1 \mathrm{~W} \text { minimum into } 50 \text { ohms with } \\ & 1.5: 1 \mathrm{SWR} \\ \text { harmonic outputs } & <-30 \mathrm{dBc} \\ \text { spurious outputs } & <-80 \mathrm{dBc}, \text { at }>20 \mathrm{kHz} \text { from carrier } \\ \text { phase noise } & <-80 \mathrm{dBc} / \mathrm{Hz} \text { at } 10 \mathrm{kHz} \text { from carrier } \\ \text { dc power } & 5 \mathrm{~V}, 0.1 \mathrm{~A} \text { max. in transmit, } \\ & 20 \mathrm{~mA} \mathrm{max.} \mathrm{in} \mathrm{receive} \\ \text { transmitter duty cycle } & 5 \mathrm{sec} \text { on, } 1 \mathrm{hr} \text { off using no external heat sink } \\ \text { humidity } & 95 \% \mathrm{max} . \\ \text { operating temperature range } & -30 \mathrm{to}+50^{\circ} \mathrm{C} \\ \text { storage temperature range } & -40 \mathrm{to}+70^{\circ} \mathrm{C} \\ \text { operating altitude } & -100 \text { to }+7000 \mathrm{ft} \\ \text { size } & 4.25 \times 2.5 \times 1.5 \text { in., max. } \\ \text { protection } & \text { thermal, SWR, over-voltage, and } \\ \text { MTBF } & \text { reverse polarity } \\ & 50,000 \mathrm{hr} \\ \end{array}$




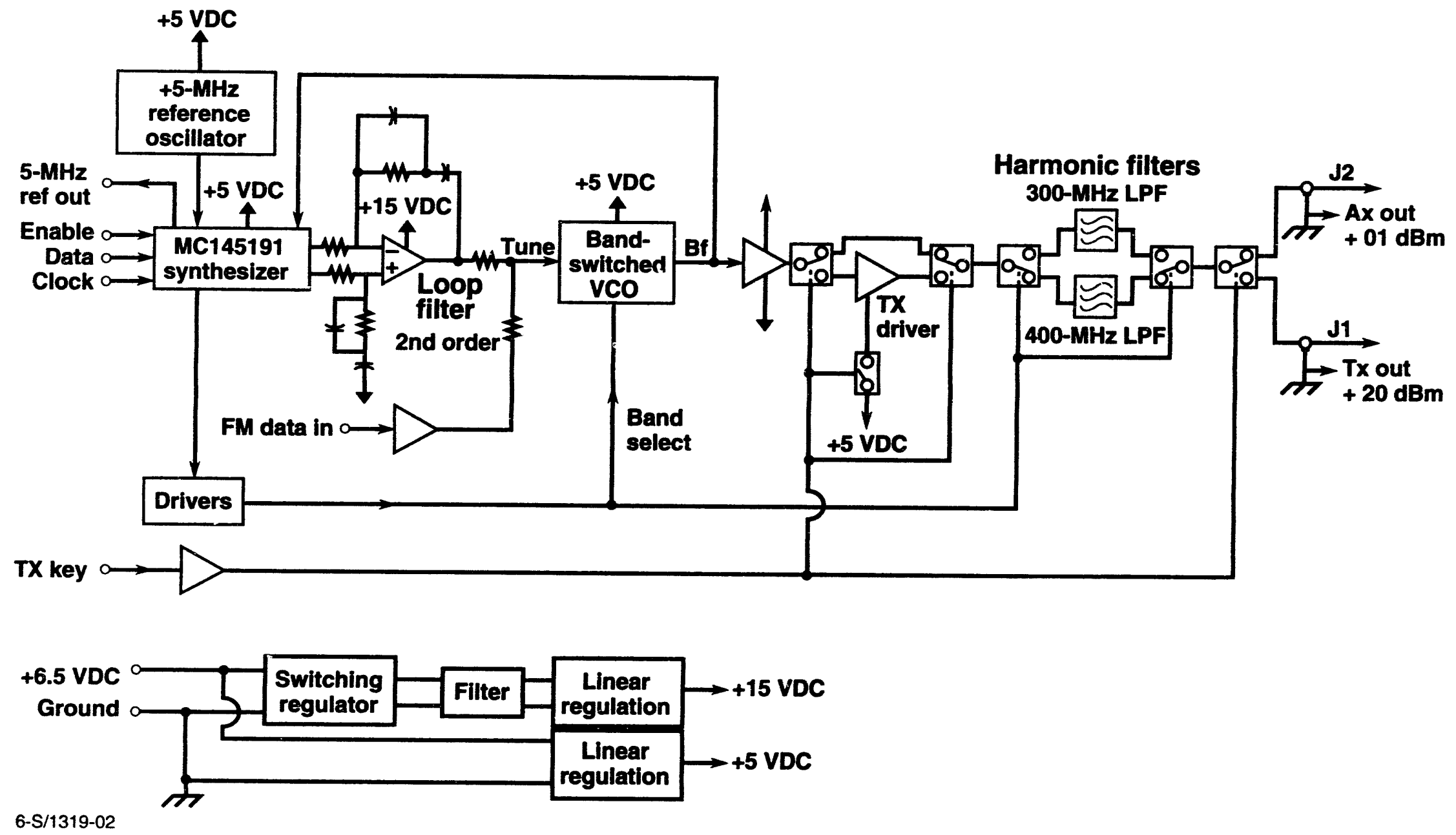

Figure 2. Block diagram of the DSI miniature synthesized exciter/transmitter. 


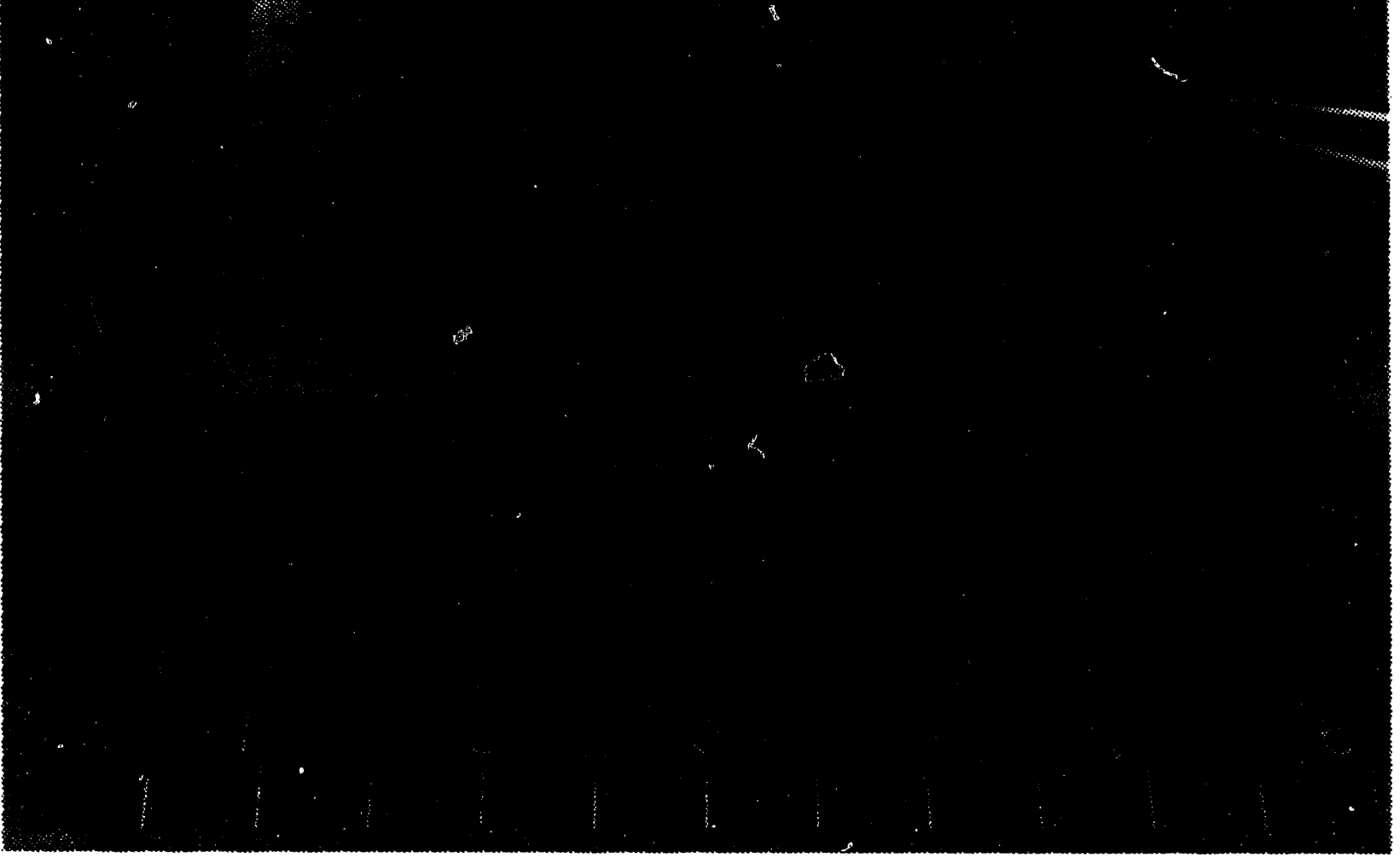

Figure 3. Photograph of the DSI miniature synthesized exciter/transmitter.

\section{Power Amplifier}

The function of the power amplifier is boosting the signal level of the exciter/transmitter output. The specified gain is that required to supply the $100-\mathrm{W}$ output with input from the exciter/transmitter.

Figure 4 is a block diagram of the power amplifier and specifications are listed in Table 2.

The amplifier component of the power amplifier was a standard component purchased from LCF* (Fig. 5).

The specified bandwidth, gain, and environmental characteristics of this unit meet system requirements. An additional lowpass filter on the output was required to meet the signal harmonic specification.

*LCF Enterprises, 651 Via Alondra, Unit 710, Camarillo, CA 93010 


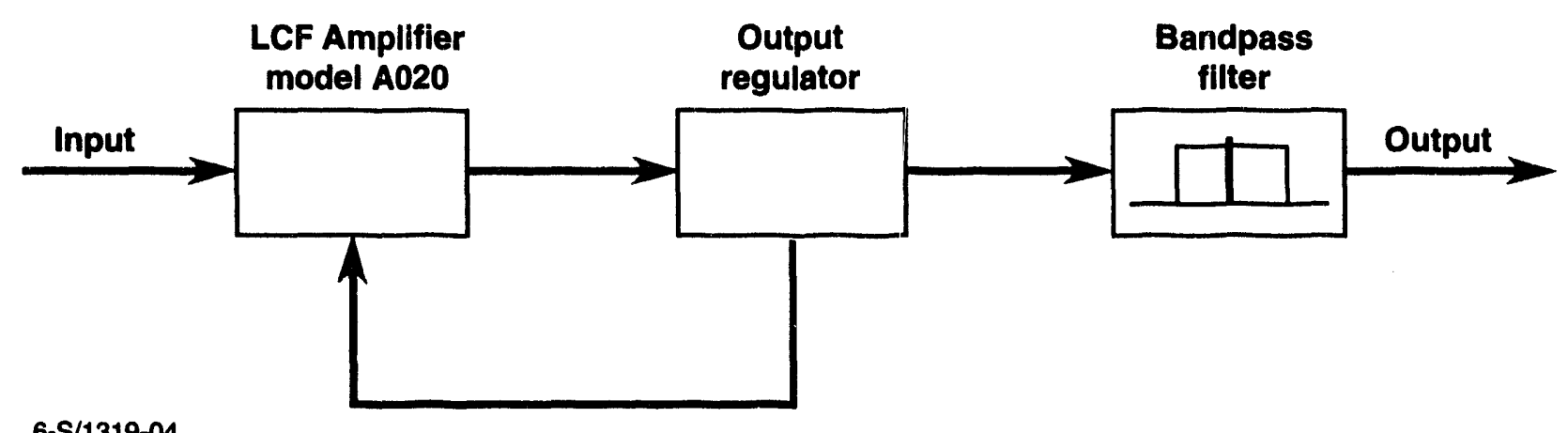

$6-S / 1319-04$

Figure 4. Diagram of a conceptual power amplifier.

Table 2. Specifications for the LCF power amplifier (purchased item).

frequency

power output

harmonic outputs

dc power

transmitter duty cycle

humidity

operating temperature range

storage temperature range

operating altitude

size

protection

MTBF
$225-400 \mathrm{MHz}$, nominal

$100 \mathrm{~W}$ minimum into $50 \mathrm{ohms}$ with

$<1.5: 1$ SWR and with $0.1 \mathrm{~W}$ input

$<-30 \mathrm{dBc}$ below $550 \mathrm{MHz}$

$<-35 \mathrm{dBc}$ above $550 \mathrm{MHz}$

when driven with signal of

$<-30 \mathrm{dBc}$ harmonic content

24 to $30 \mathrm{Vdc}, 9 \mathrm{~A}$,

maximum while transmitting,

0 A. while in standby

$5 \mathrm{sec}$ on, $1 \mathrm{hr}$ off using no

external heat sink

$95 \%$ max.

-30 to $+50^{\circ} \mathrm{C}$

-40 to $+70^{\circ} \mathrm{C}$

-100 to $+7000 \mathrm{ft}$

$4.85 \times 2.5 \times 1.5$ in., max.

thermal, SWR, over-voltage,

and reverse polarity

$50,000 \mathrm{hr}$ 


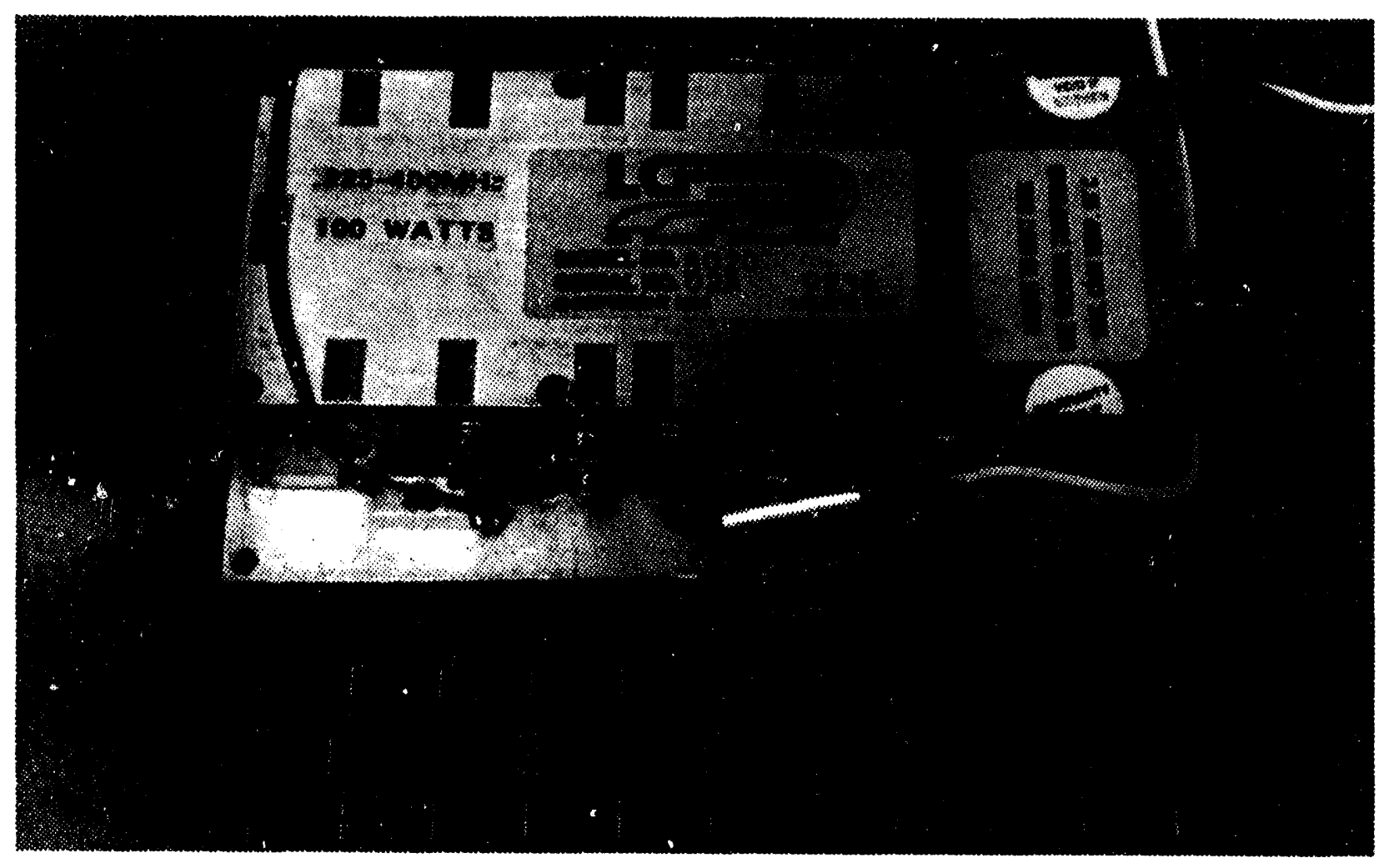

Figure 5. Photograph of the LCF power amplifier

The amplifier has been tested for conformance with specifications for power output and gain at room temperature. Support precluded the evaluation over the full environmental range.

Note is that the LCF unit is specified for $+28 \mathrm{Vdc}$; both gain and output power are reduced by about $15 \%$ when operated at $24 \mathrm{Vdc}$. LCF indicated that the design could be modified to meet the operational specifications at the lower supply voltage.

Amplifier output regulation and protection, and signal filters were designed by LLNL. In testing the power-amplifier subsystem readily delivered $100 \mathrm{~W}$ of output power over the entire band with less than $-40 \mathrm{dBc}$ harmonic content. 


\section{Command Receiver}

The command receiver provides an rf command and control link to the remote sensor unit. This application requires a receiver with the following design features:

- low power

- reasonably narrow bandwidth

- power control (to implement power saving)

- BPSK to achieve optimum performance in noise background

The receiver bandwidth, noise figure, and demodulation format were obtained from a trade-off analysis that considered such factors as the expected command-source signal levels (minimum with fluctuations and fading), receiver antenna gain and noise figures, required bit error rate (BER) and maximum data transmission rate, energy requirements, and operating time. Table 3 lists the set of specifications for the command receiver meeting these requirements.

A block diagram of the POC receiver is shown in Fig. 6. This design uses a local oscillator (supplied by the synthesized exciter/transmitter), an input amplifier and filter, an up-converter, an IF amplifier, and a BPSK demodulator and clock recovery circuit. The IF amplifier is an NCI

Table 3. Specifications for the command receiver.

frequency

frequency stability

sensitivity

adjacent channel selectivity

spurious responses

intermodulation immunity

modulation

receiver bandwidth

phase noise

dc power

humidity

operating temperature range

storage temperature range

operating altitude

size

protection

MTBF
240-270 MHz, nominal

$\pm 1 \mathrm{ppm}$ over temperature range

and over 2 years' aging

$<0.25 \mu \mathrm{V}$ for $10^{-5} \mathrm{BER}$

$70 \mathrm{~dB} @ \pm 5 \mathrm{kHz}$

$70 \mathrm{~dB}$

$60 \mathrm{~dB}$ at reference sensitivity

BPSK, 100 bps, TTL output

$1 \mathrm{kHz}$

$<-80 \mathrm{dBc} / \mathrm{Hz}$ at $10 \mathrm{kHz}$

$5 \mathrm{~V}, 20 \mathrm{~mA}$

$95 \% \max$.

-30 to $+50^{\circ} \mathrm{C}$

-40 to $+70^{\circ} \mathrm{C}$

-100 to $+7000 \mathrm{ft}$

$4.25 \times 2.5 \times 1.0$ in.

over-voltage, and reverse polarity

$50,000 \mathrm{hr}$ 
Systems receiver, model NCD1003*; it operates at a $400-\mathrm{MHz}$ center frequency. The upconverter translates the $240-270-\mathrm{MHz}$ satellite communications downlink band to the IF frequency. The LLNL-designed BPSK demodulator and clock recovery recovers the message bitstream and transfers these data into the microcontroller. This developmental receiver is packages in a utility enclosure, shown in Fig. 7.

The receiver sensitivity has been measured at $0.3 \mathrm{mV}$. Assuming receiver noise to the limiting system factor, a BER of $10^{-5}$ over the $\mathrm{MHz}$ band should be supported. Tests characterizing the receiver where limited to sensitivity, noise, measurement of the passband, and power requirements. This characterization indicated that the receiver noise is about $6 \mathrm{~dB}$ greater than the design goal of $\mathrm{C} / \mathrm{N}$ of $0 \mathrm{~dB}$.

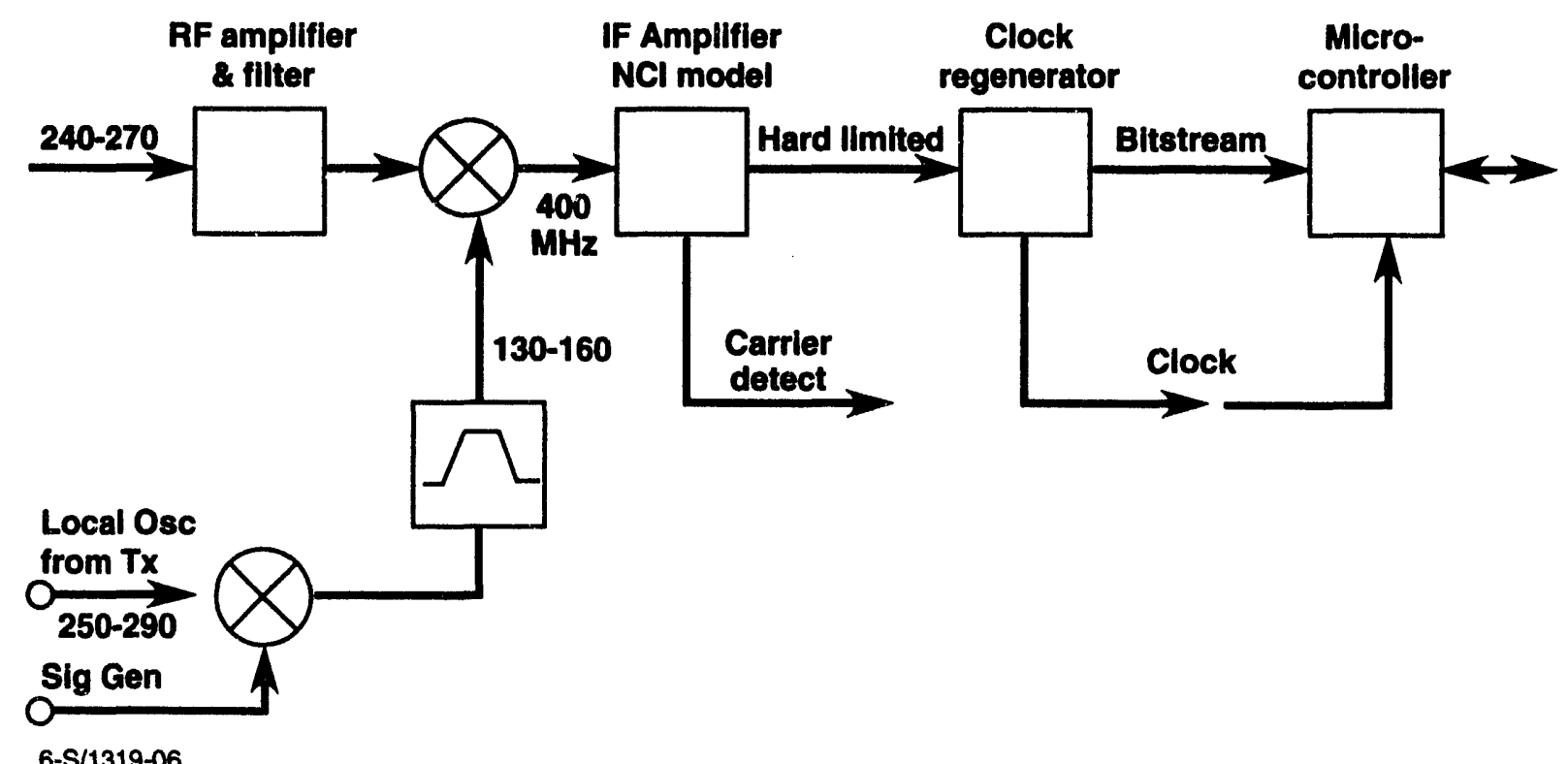

Figure 6. Diagram of the proof-of-concept command receiver. 


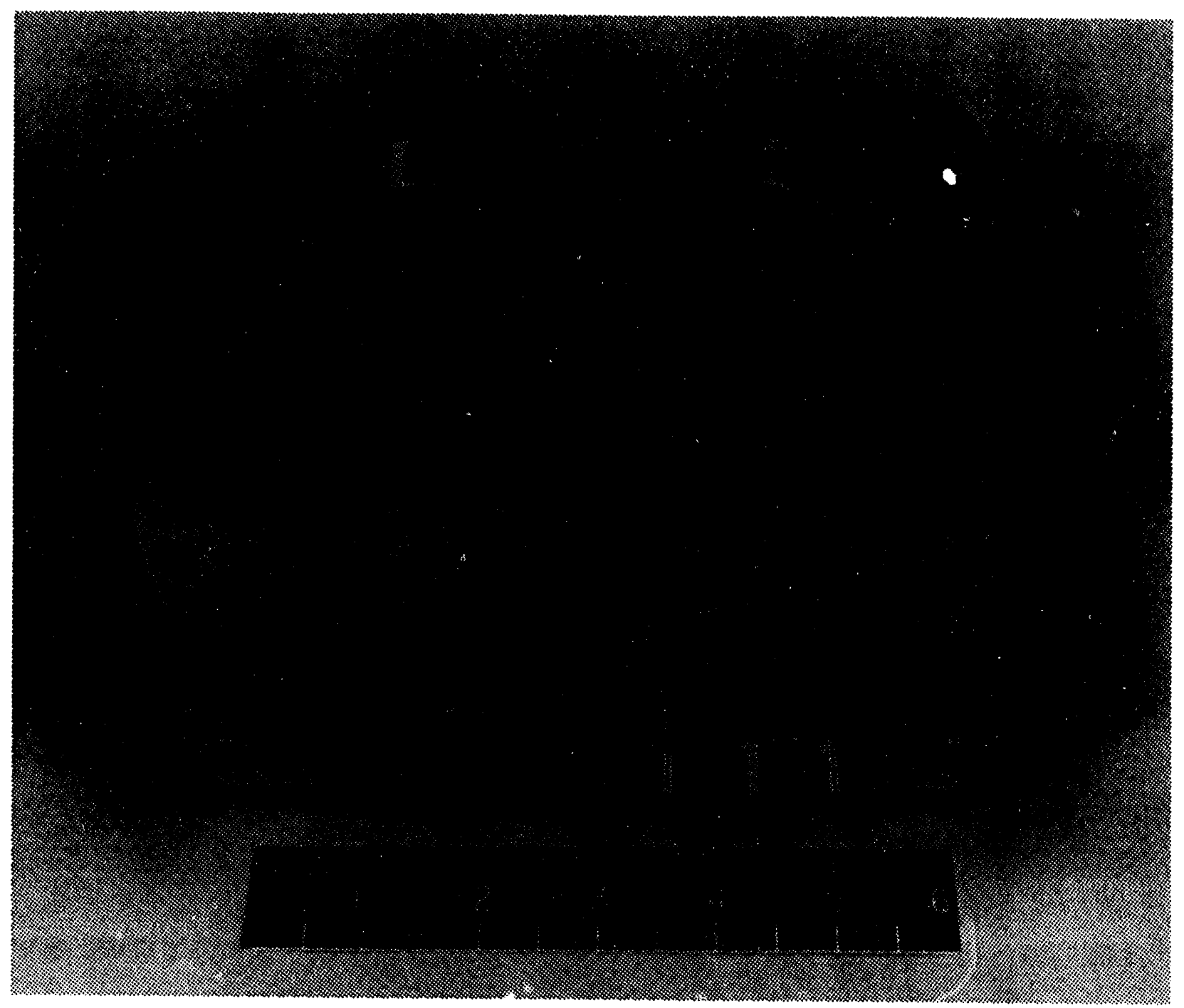

Figure 7. Photograph of the proof-of-co icept command receiver. 


\section{Appendix A. Exciter/transmitter Test Data*}

A block diagram of the exciter/transmitter is shown by Fig. A-1. This design is based around a band-switched, voltage-controlled oscillator (VCO); the VCO schematic is given in Fig. A-2. The VCO operates in two ranges-225.000-300.00 MHz and 300.005-400.000 MHz. The VCO output is lowpass-filtered to reduce the harmonic signals. The filtered rf signal is steered to one of two outputs: a $+10 \mathrm{dBm}$ receiver local oscillator reference, or a $+20 \mathrm{dBm}$ transmitter output. The output transmitter power and the required supply current over the specified range of frequency and temperature (range of -20 to $+50 \circ \mathrm{C}$ ) are given in Figs. A-3 through A-8. The measured spectrum of the output is shown in Figs. A-9 and A-10; these data were taken at $+50^{\circ} \mathrm{C}$ and $30^{\circ} \mathrm{C}$, respectively.

The VCO is frequency-modulated (linear FM/FSK) by controlling the loop error voltage with the information signal. The nominal modulation sensitivity results in a $25-\mathrm{kHz}$ frequency deviation $( \pm 12.5 \mathrm{kHz})$ about the carrier frequency. The loop gain (sensitivity) changes as the VCO frequency is varied (by changing the feedback counter ratio). Thus, the level of the modulation signal must be varied to maintain the $25-\mathrm{kHz}$ carrier deviation. The gain variation required to maintain the carrier deviation is illustrated in Fig. A-11.

The VCO loop bandwidth also sets a lower data rate (frequency) limit for the modulation signal. Figures A-12 through A-17 illustrate the phase shift in a $40-\mathrm{Hz}$ square wave at various rf carrier frequencies.

The programming sequence for the VCO is defined in Fig. A-18. A communications interface was designed to adapt this interface to the MISS bus. A block diagram of the interface is shown in Fig. A-19 and is illustrated in Fig. A-20. Figure A-21 shows the test setup ("breadboard").

*These experimental data were provided by the contractor, Defense Systmes Inc., 1521 Westbranch Drive, McLean, Va 220102 


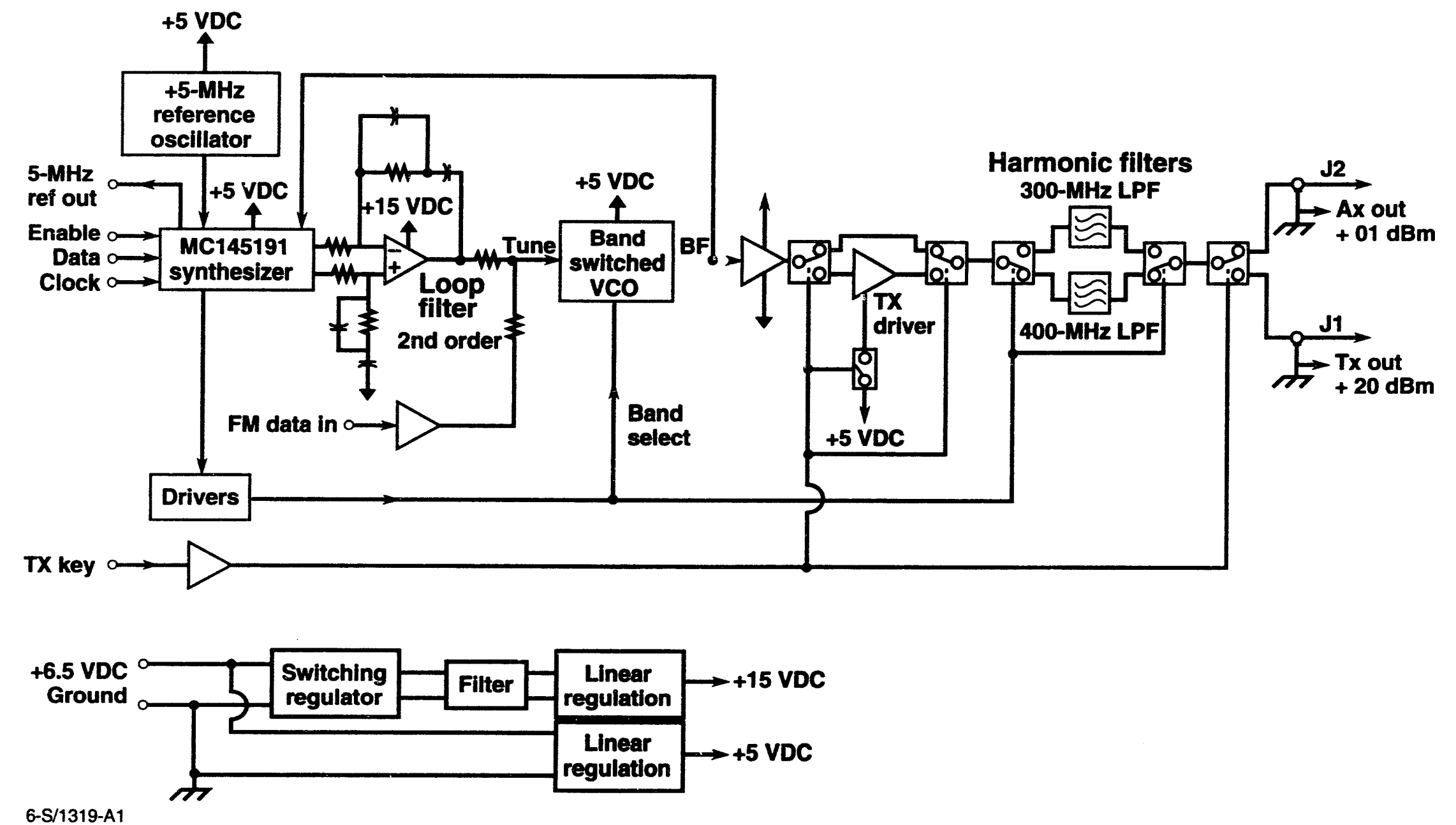

Figure A-1. Diagram of the DSI miniature synthesized exciter/transmitter loop block diagram. 
N

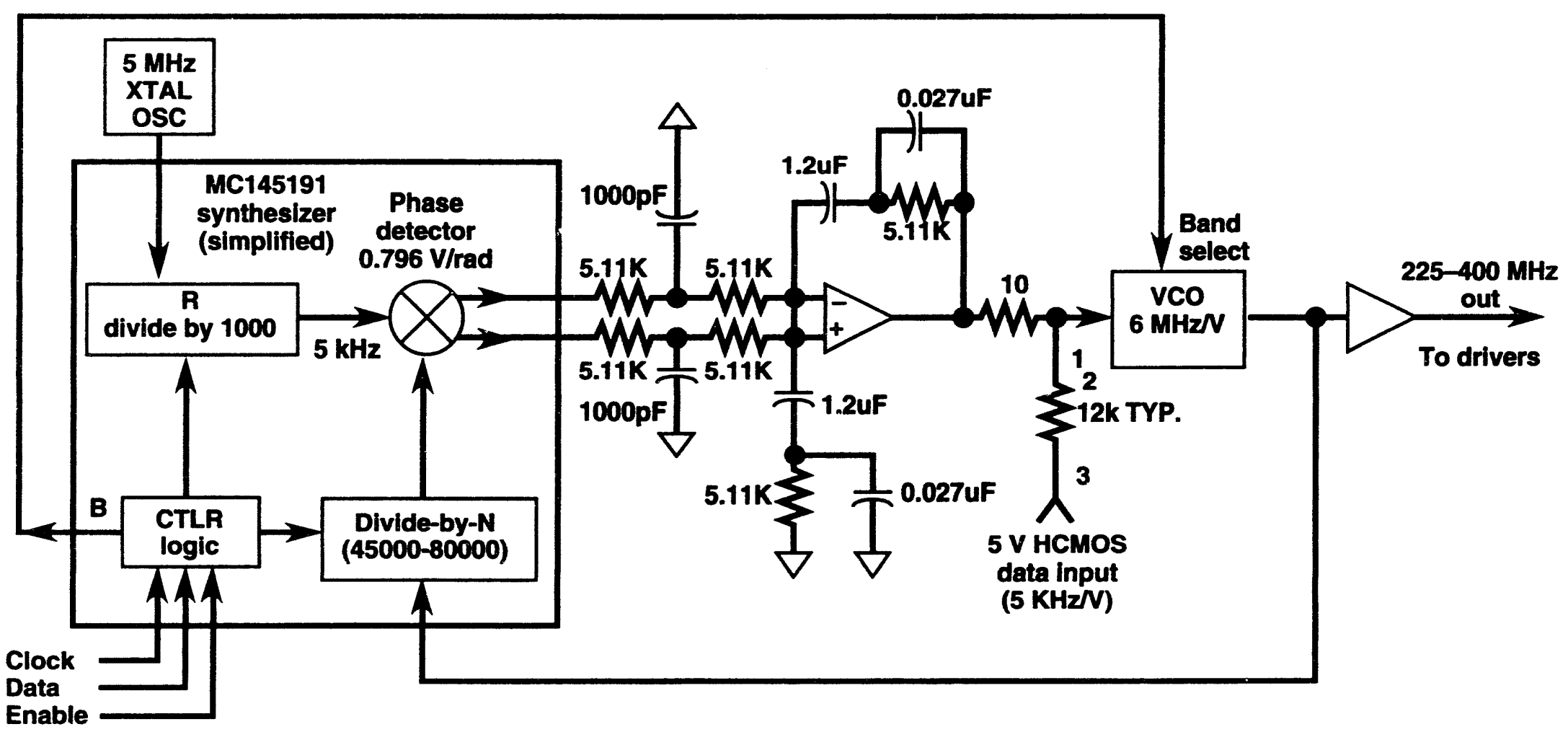

Loop phase margin $=45$ degrees

Loop natural frequency $=50 \mathrm{~Hz}$

Loop time constant $=0.02 \mathrm{sec}$

6-S/1319-A2

Figure A-2. Synthesizer-loop block diagram. 


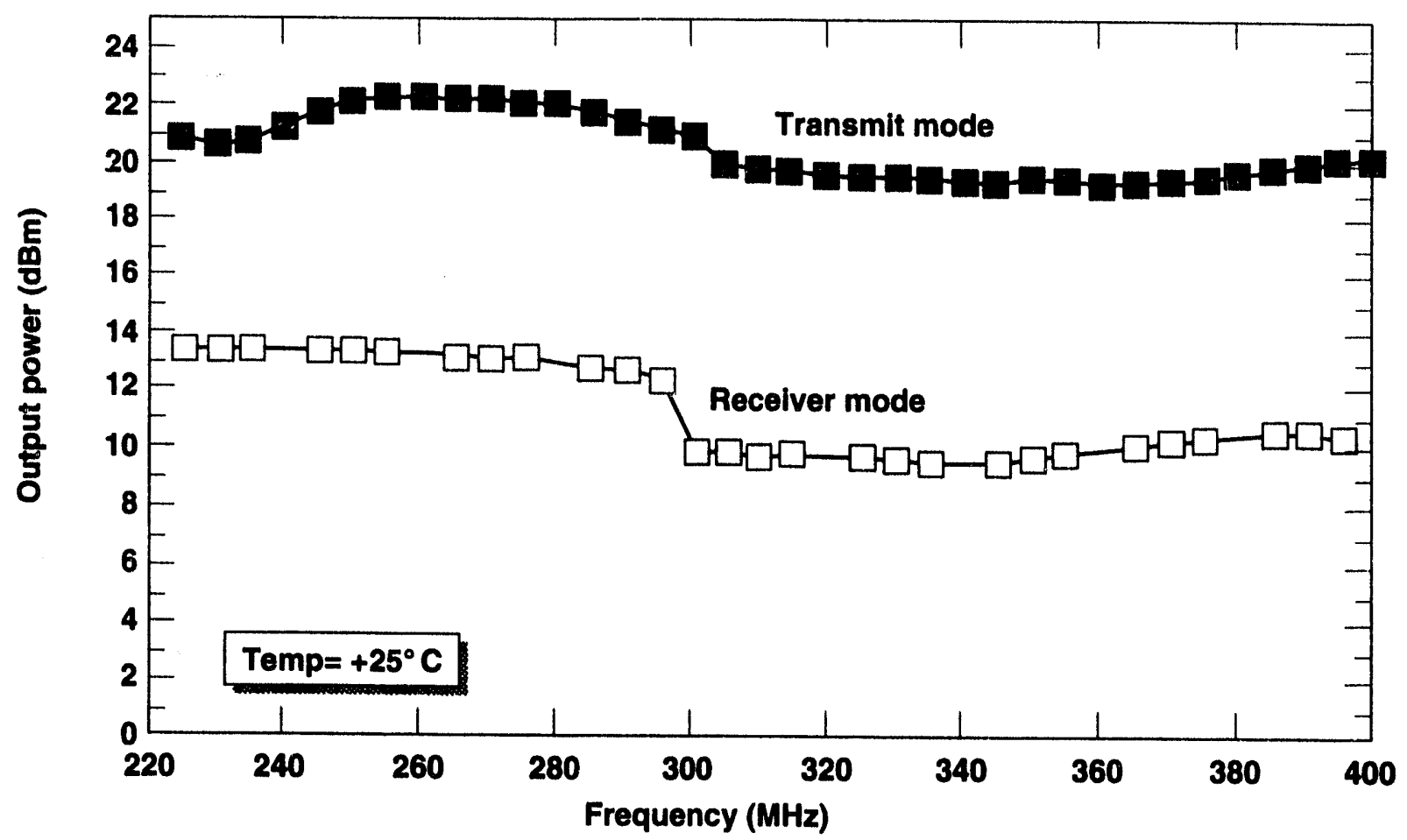

6-S/1319-A3

Figure A-3. Output power as a function of frequency at $+25^{\circ} \mathrm{C}$.

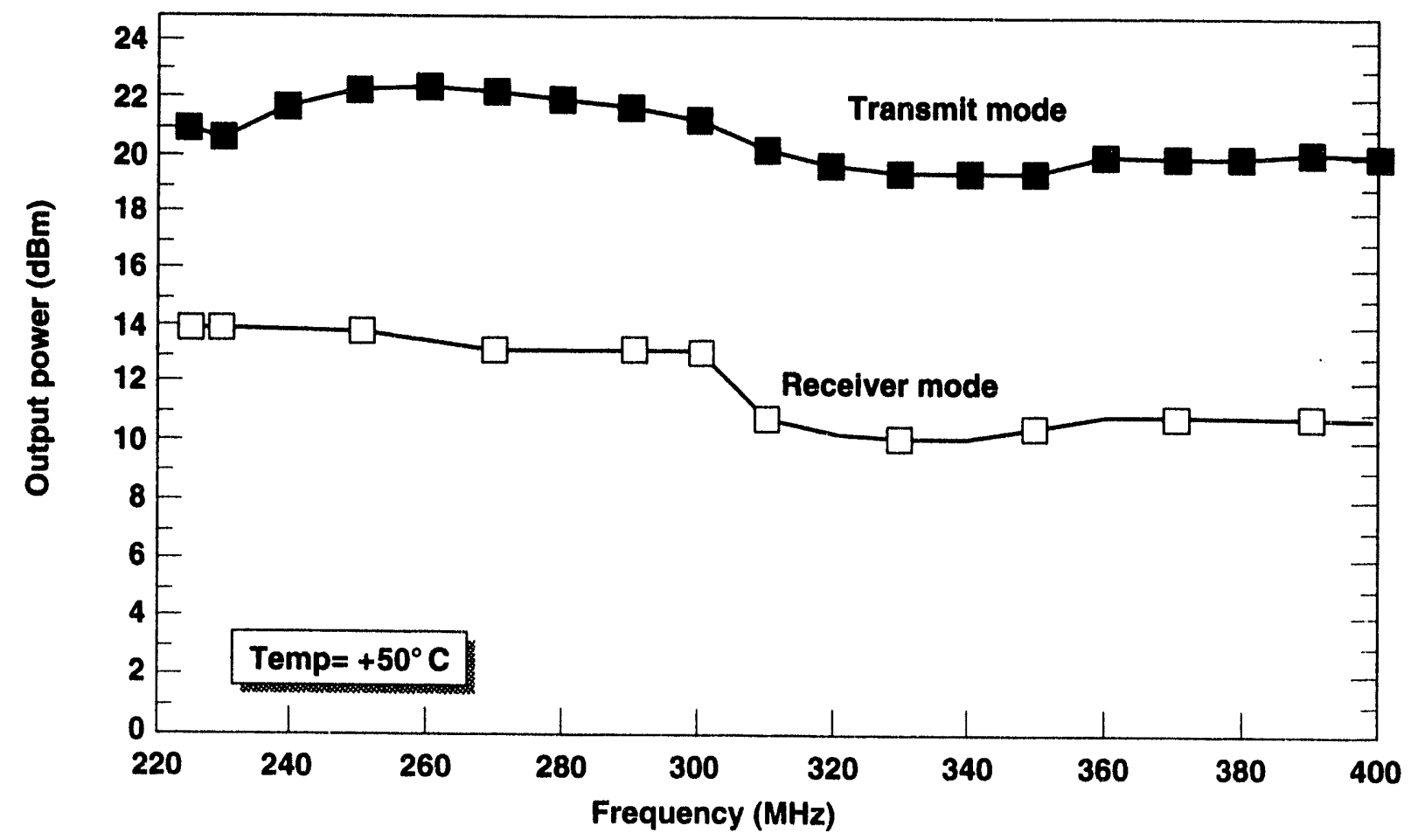

6-S/1319-A4

Figure A-4. Output power as a function of frequency at $+50^{\circ} \mathrm{C}$.. 


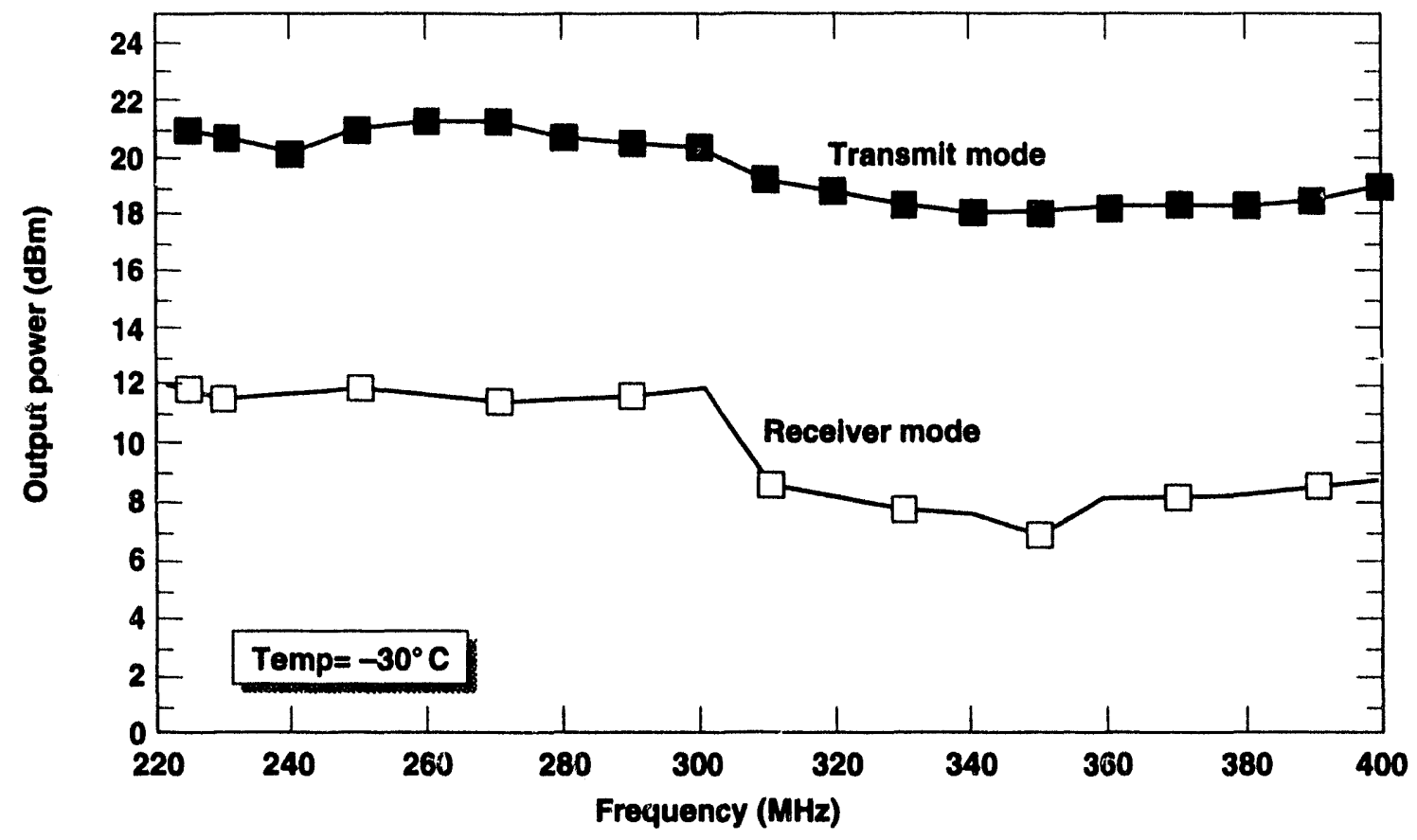

6-S/1319-A5

Figure A-5. Output power as a function of frequency at $-30^{\circ} \mathrm{C}$.

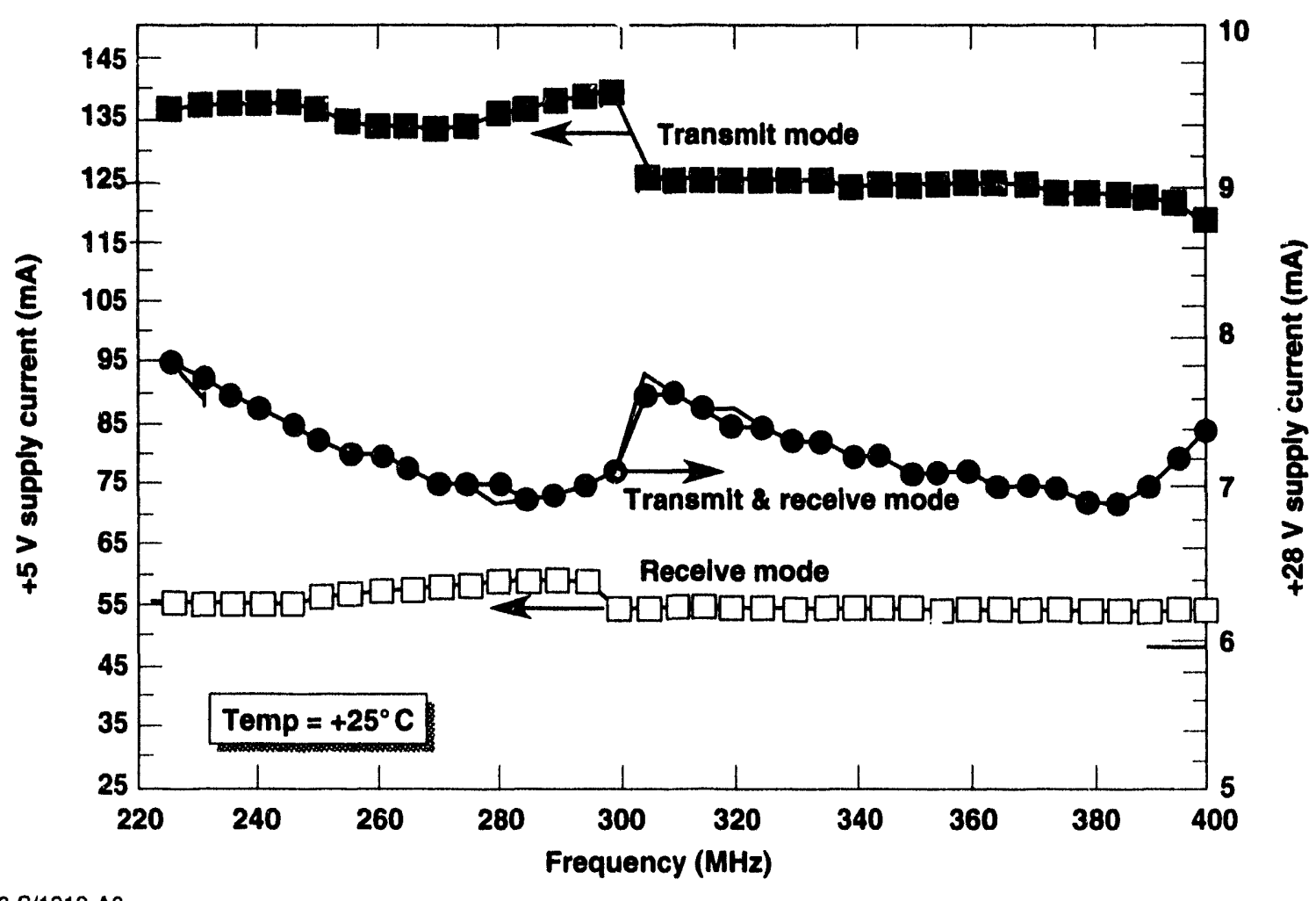

6-S/1319-A6

Figure A-6. Supply current as a function of frequency at $+25^{\circ} \mathrm{C}$. 


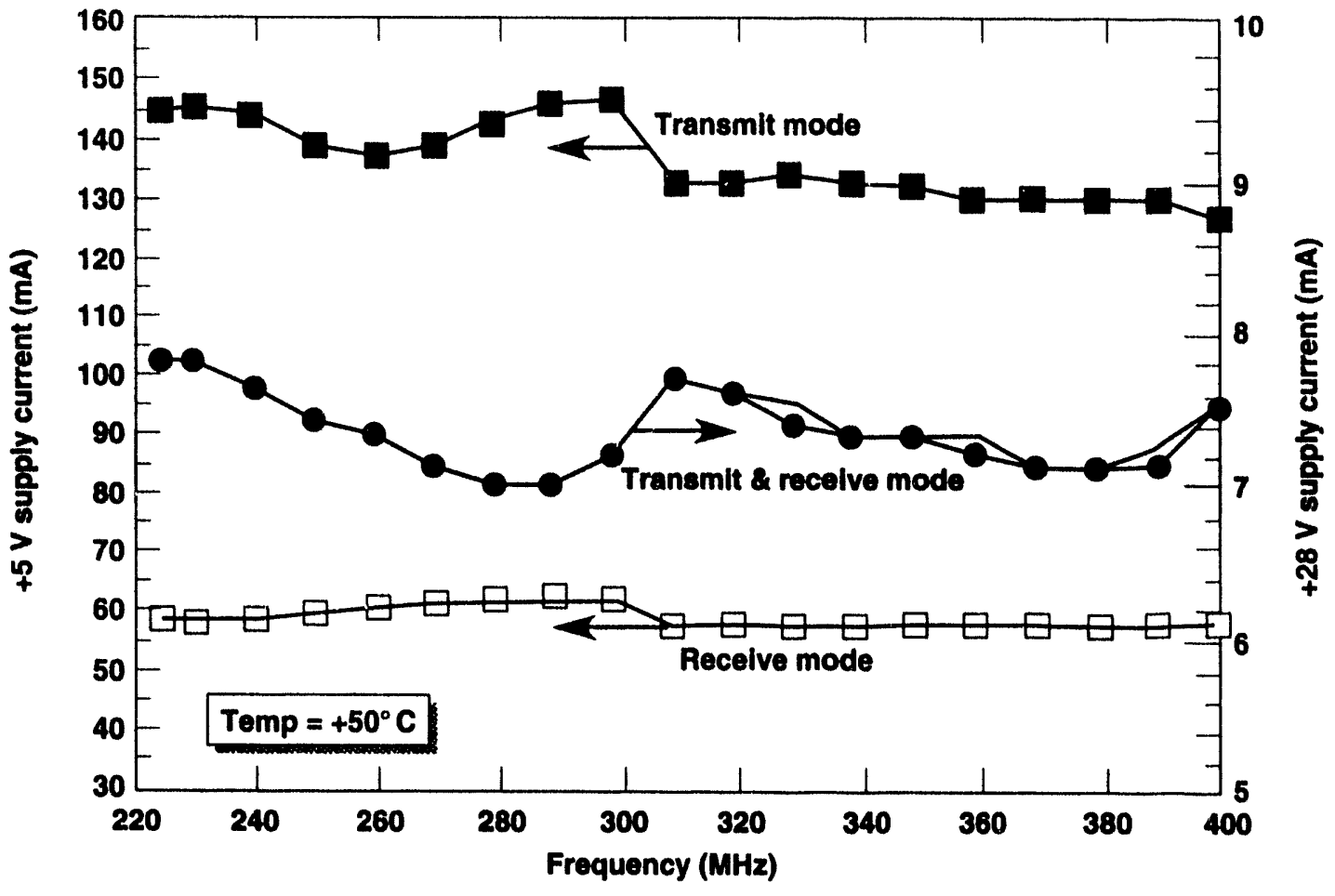

6-S/1319-A7

Figure A-7. Supply current as a function of frequency at $+50^{\circ} \mathrm{C}$.

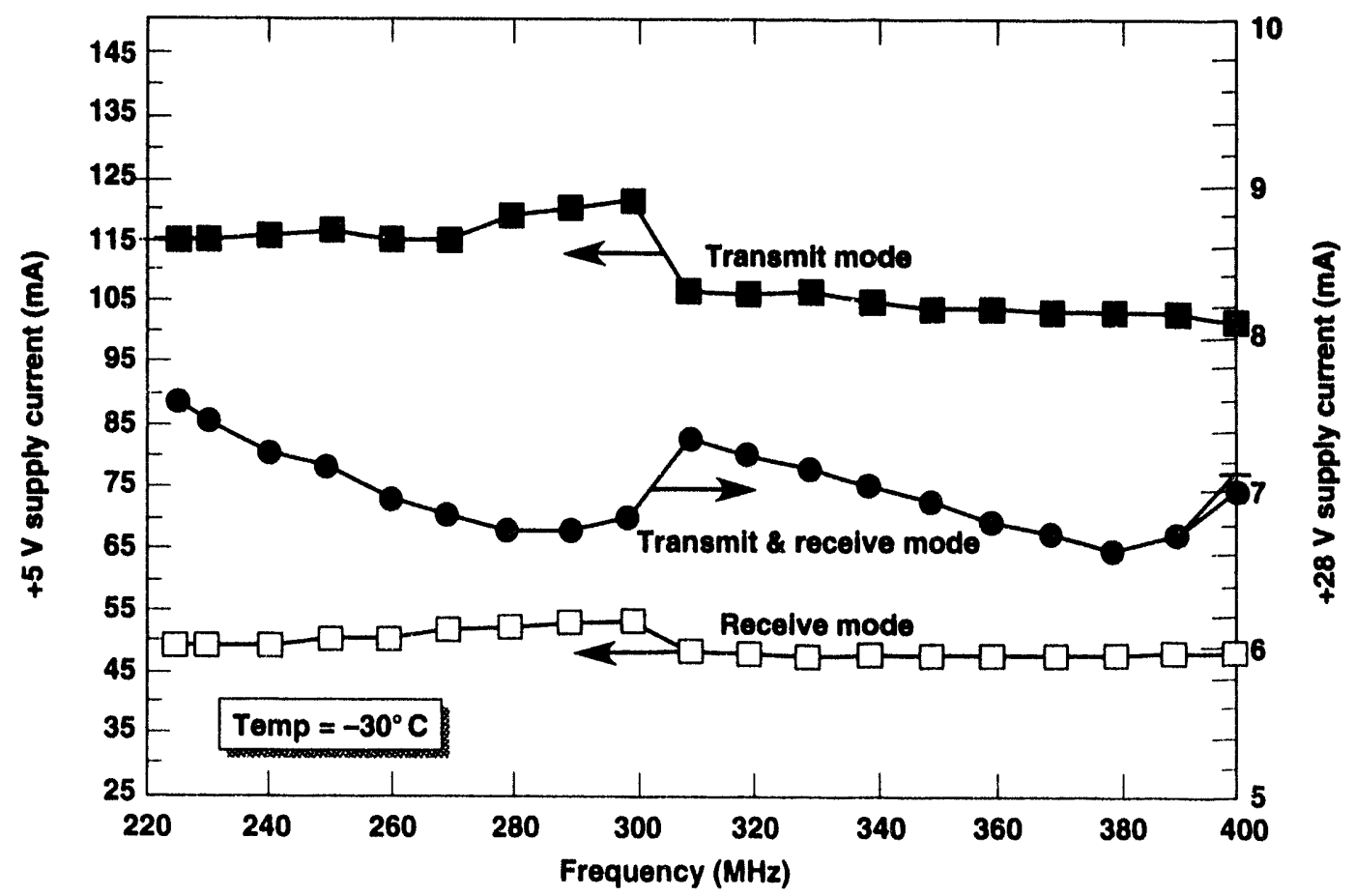

6.S/1319-AB

Figure A-8. Supply current as a function of frequency at $-30^{\circ} \mathrm{C}$. 


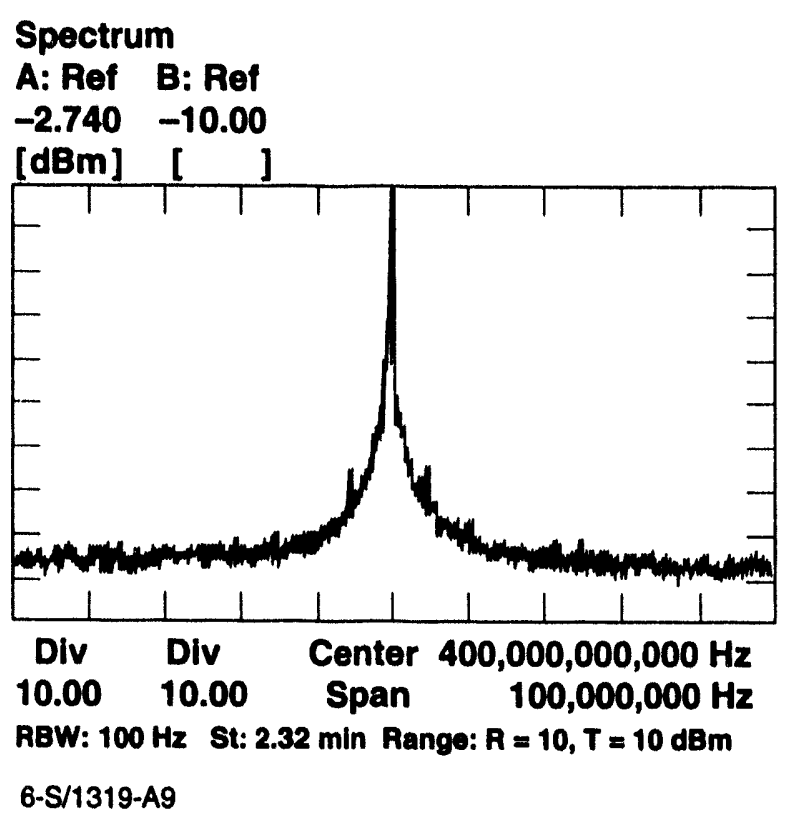

Figure A-9. Phase noise spectrum, $100 \mathrm{kHz}$ about $400 \mathrm{MHz}$ at $+50^{\circ} \mathrm{C}$.

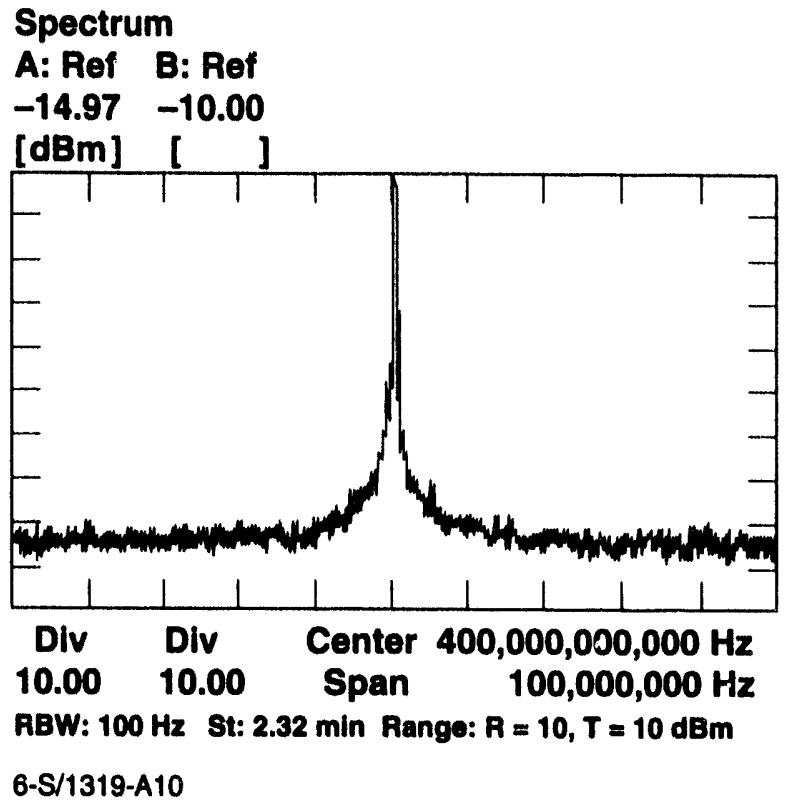

Figure A-10. Phase noise spectrum, $100 \mathrm{kHz}$ about $400 \mathrm{MHz}$ at $\neq 30^{\circ} \mathrm{C}$.

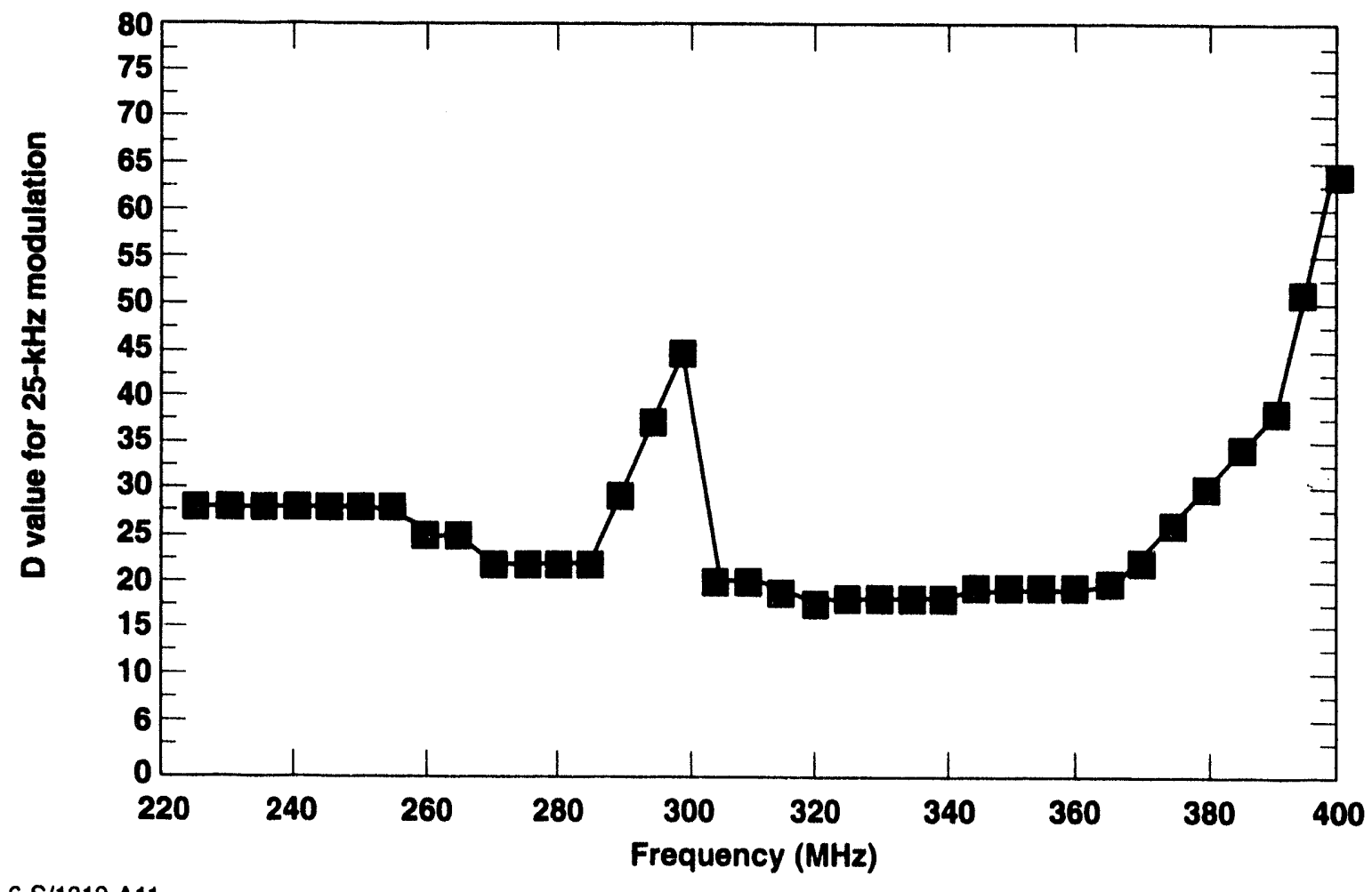

6-S/1319-A11

Figure A-11. Modulation amplitude control gain for constant 25-kHz frequency deviation. 


\section{Ref $20.0 \mathrm{dBm} \quad$ Atten $30 \mathrm{~dB}$}

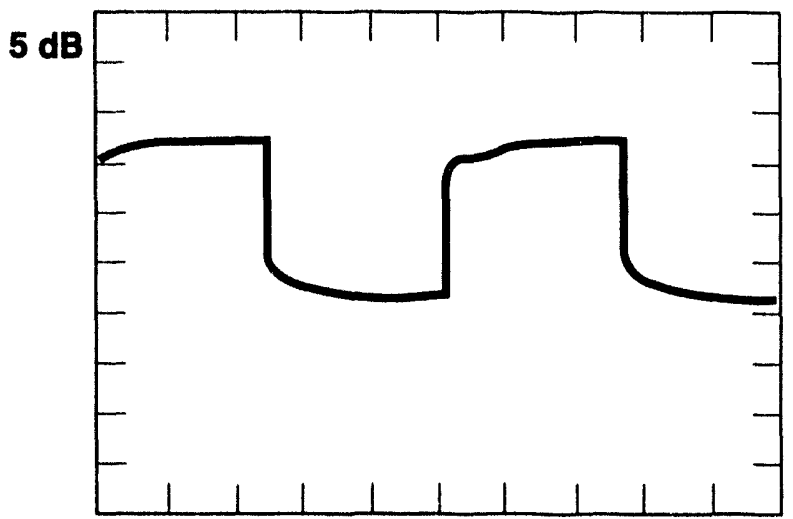

Center 224.9610 MHz

Span $0 \mathrm{~Hz}$

Res BW $30 \mathrm{kHz}$ VBW $30 \mathrm{kHz}$ SWP 50 msec 6-S/1319-A12

Figure A-12. Demodulated exciter/ transmitter output, $40 \mathrm{~Hz}$ modulation, 225 $\mathrm{MHz}$ center frequency.

\section{Ref $20.0 \mathrm{dBm}$ Atten $30 \mathrm{~dB}$}

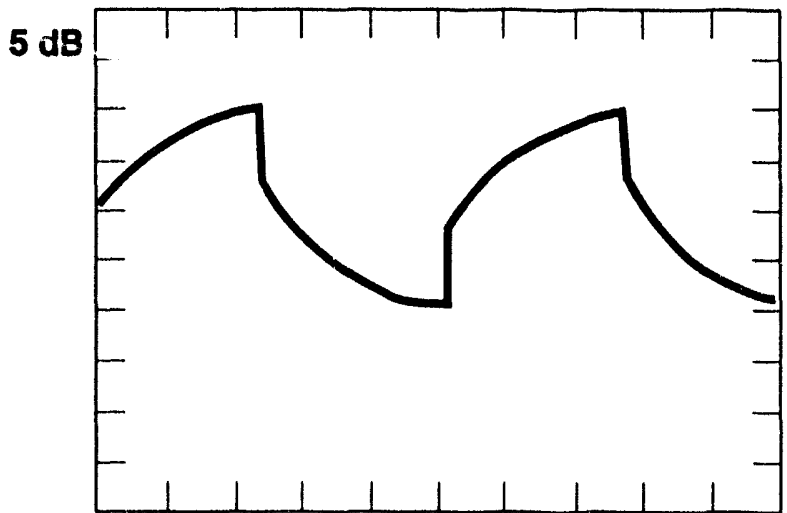

\section{Center 299.9633 MHz}

Span $\mathrm{OHz}$

Res BW $30 \mathrm{kHz}$ VBW $10 \mathrm{kHz}$ SWP 50 msec 6-S/1319-A14

Figure A-14. Demodulated exciter/ transmitter output, $40 \mathrm{~Hz}$ modulation, $300 \mathrm{MHz}$ center frequency.

\section{Ref $\mathbf{3 0 . 0} \mathrm{dBm} \quad$ Atten $\mathbf{4 0} \mathrm{dB}$}

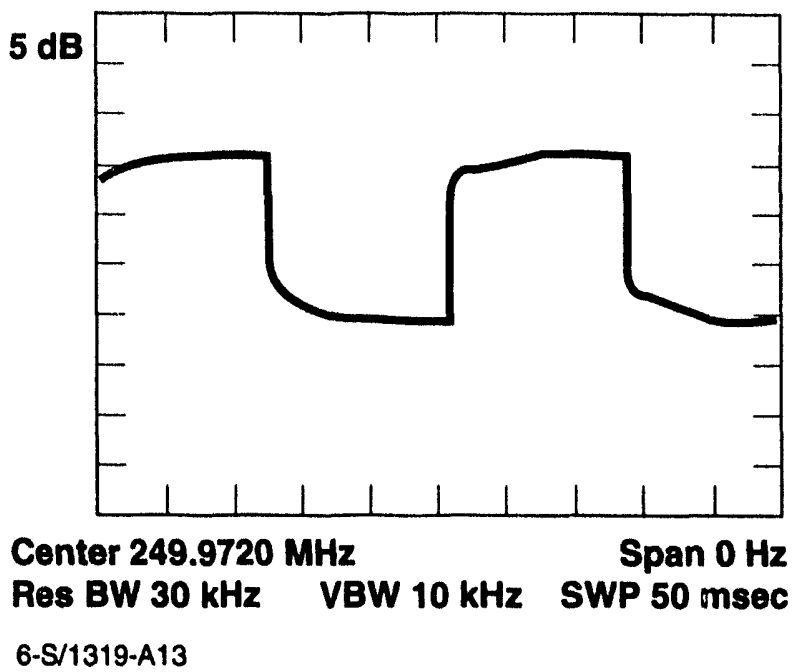

Figure A-13. Demodulated exciter/ transmitter output, $40 \mathrm{~Hz}$ modulation, $250 \mathrm{MHz}$ center frequency.

\section{Ref $20.0 \mathrm{dBm} \quad$ Atten $\mathbf{3 0} \mathrm{dB}$}

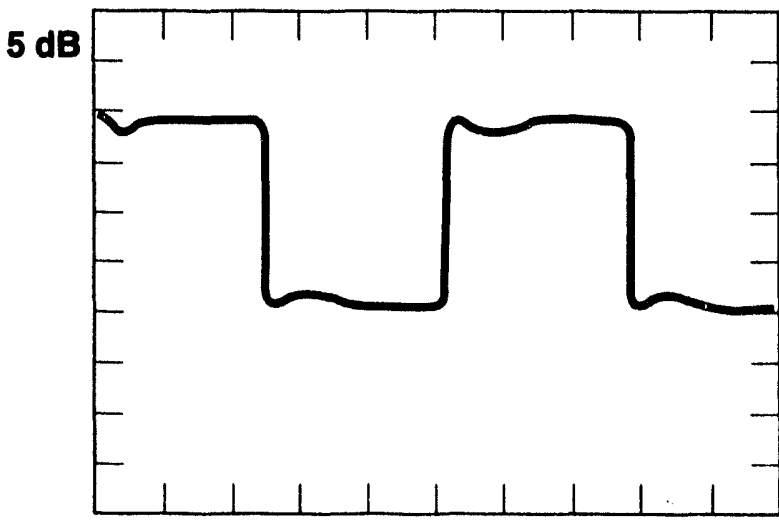

Center $300.9640 \mathrm{MHz}$

Span $\mathrm{OHz}$

Res BW $30 \mathrm{kHz}$ VBW $10 \mathrm{kHz}$ SWP 50 msec 6-S/1319-A15

Figure A-15. Demodulated exciter/ transmitter output, $40 \mathrm{~Hz}$ modulation, $301 \mathrm{MHz}$ center frequency. 
Ref $20.0 \mathrm{dBm}$ Atten $30 \mathrm{~dB}$

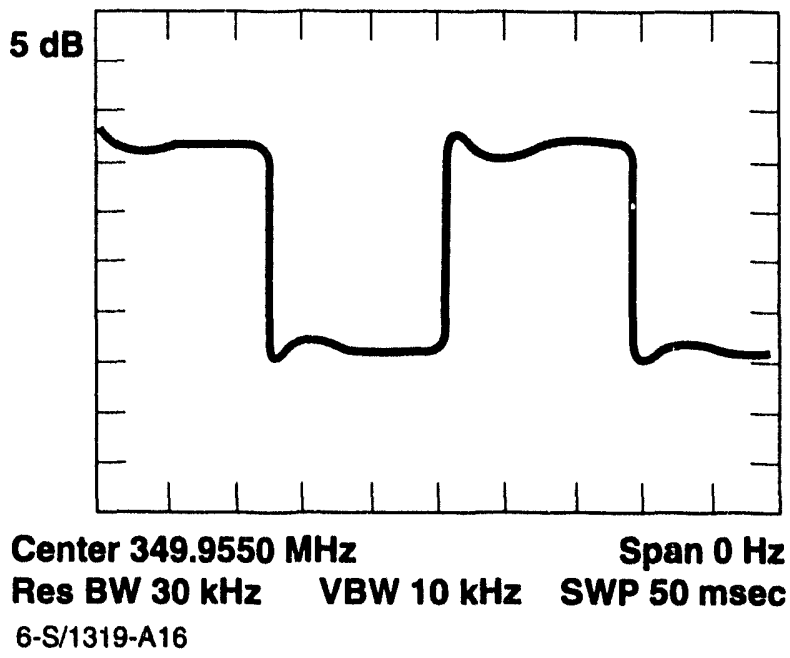

Figure A-16. Demodulated exciter/ transmitter output, $40 \mathrm{~Hz}$ modulation, $350 \mathrm{MHz}$ center frequency.
Ref $20.0 \mathrm{dBm}$ Atten $30 \mathrm{~dB}$

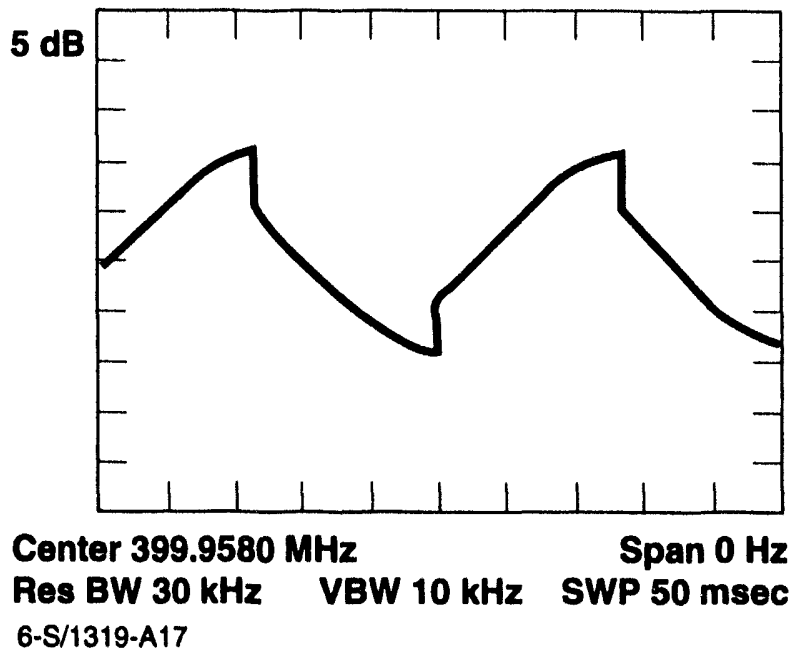

Figure A-17. Demodulated exciter transmitter output, $40 \mathrm{~Hz}$ modulation, $400 \mathrm{~Hz}$ modulation, center frequency.

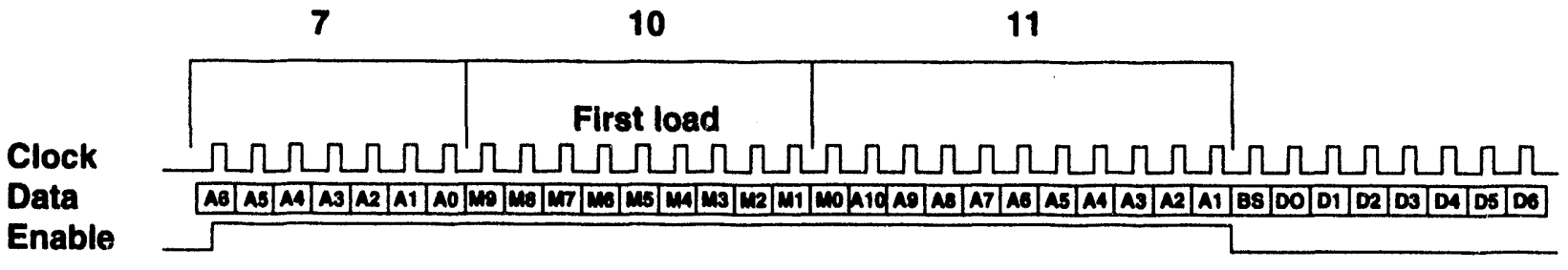

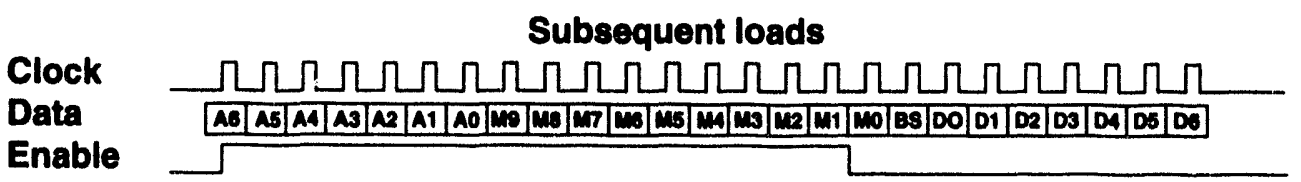

$F=$ Synthesizer output frequency

$P=F / 5000 \mathrm{~Hz}$

$M=$ Integer (P/128) (10 Bits) $\quad B S=0$ if $F<300 \mathrm{MHz} ; 1$ if $F>=300 \mathrm{MHz}$

$A=P-128 * M \quad$ ( 7 Bits)

FM Deviation - D/128 *30 kHz peak-to-peak

The $A$ register need only be loaded on the first programming.

TX key enables 100-mW output when high, 10-mW output when low.

TX data is NRZ data preferably with no spectral components below $200 \mathrm{~Hz}$.

Out-of-lock (OOL) pin is low when the synthesizer is locked.

All pins are HCMOS compatible.

6-S/1319-A18

Figure A-18. Synthesizer programming sequence. 


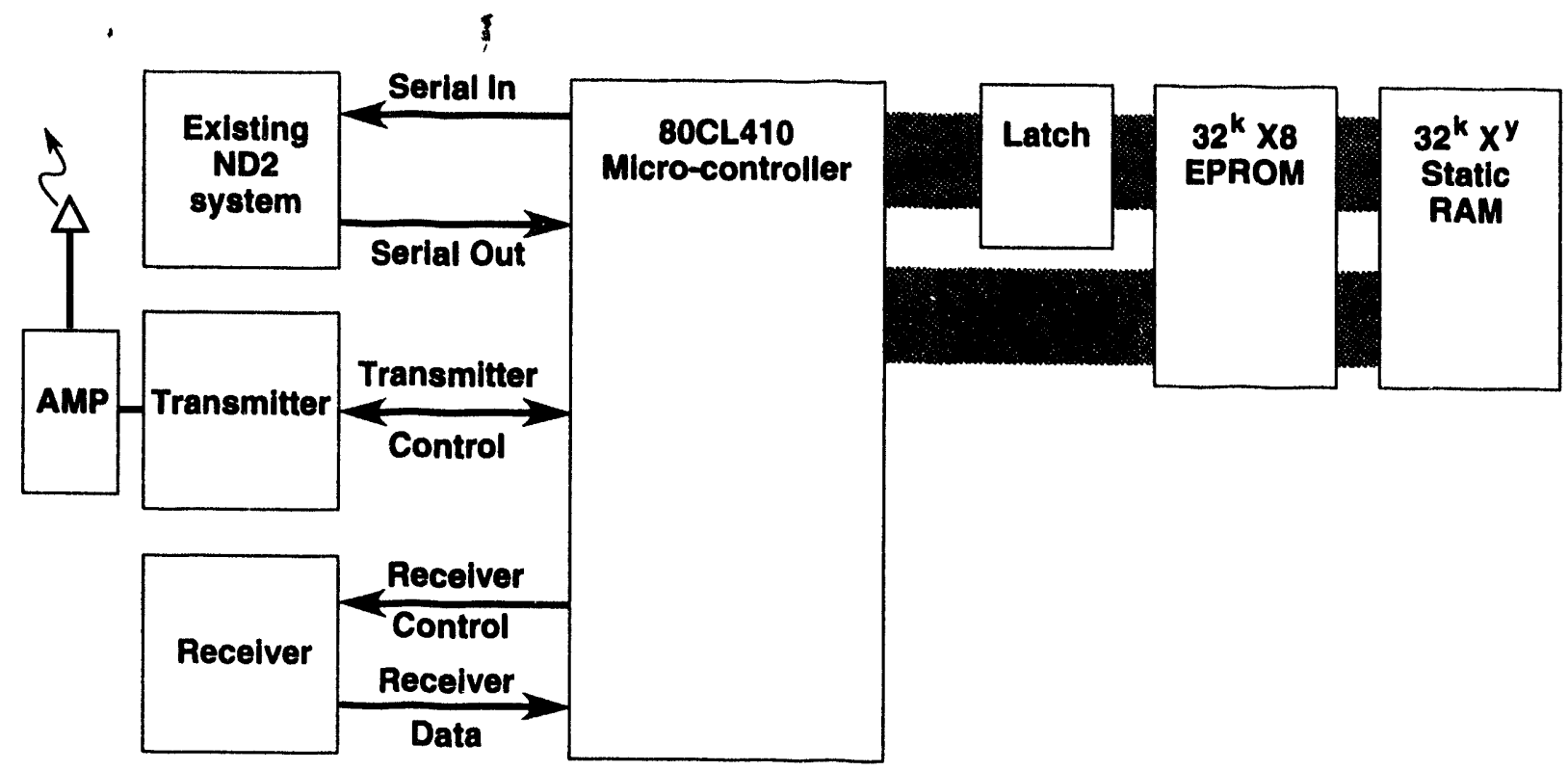

6-S/1319-A19

Figure A-19. Block diagram of MISS bus communication interface. 


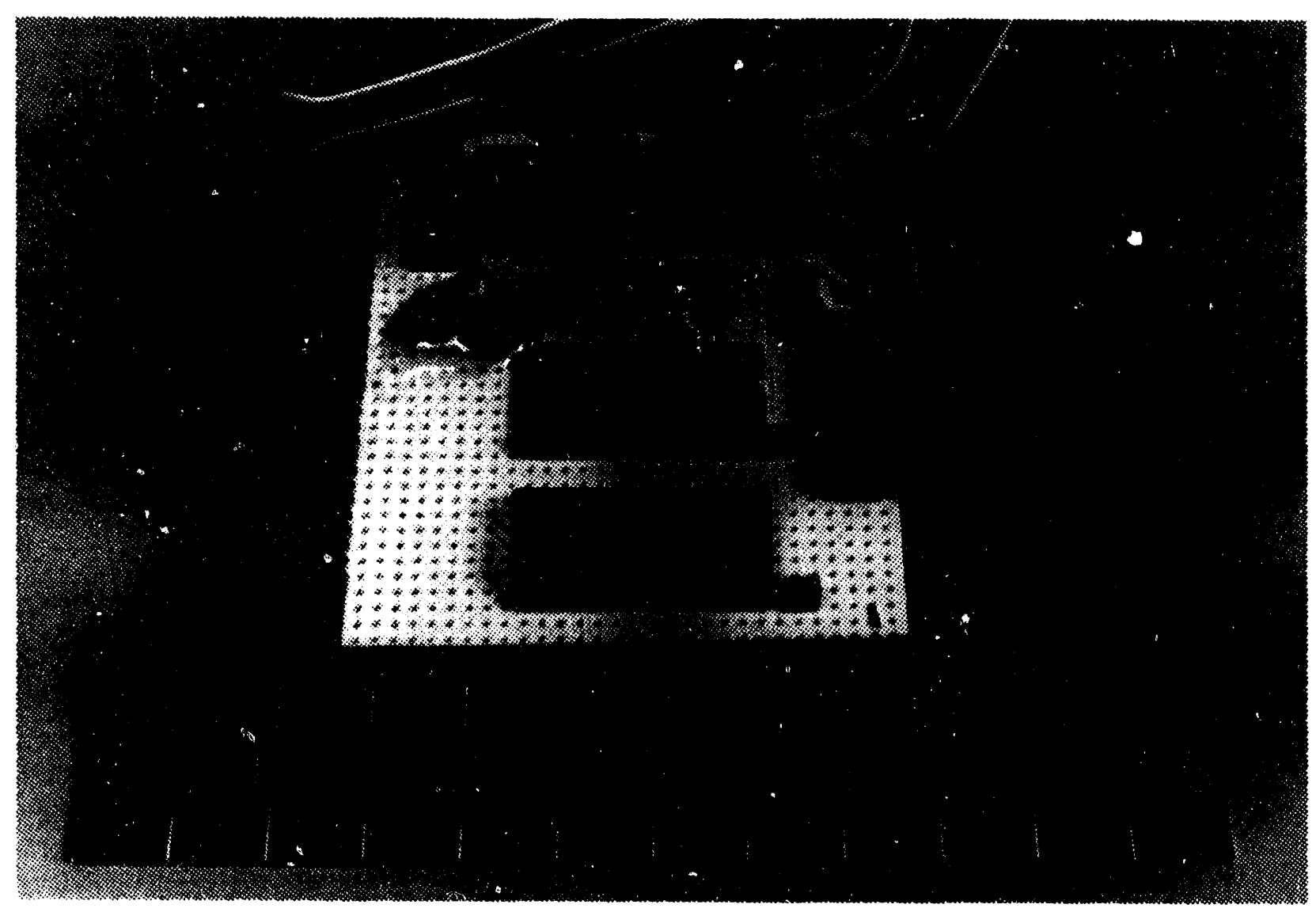

Figure A-20. Photograph of the MISS bus communication interface. 


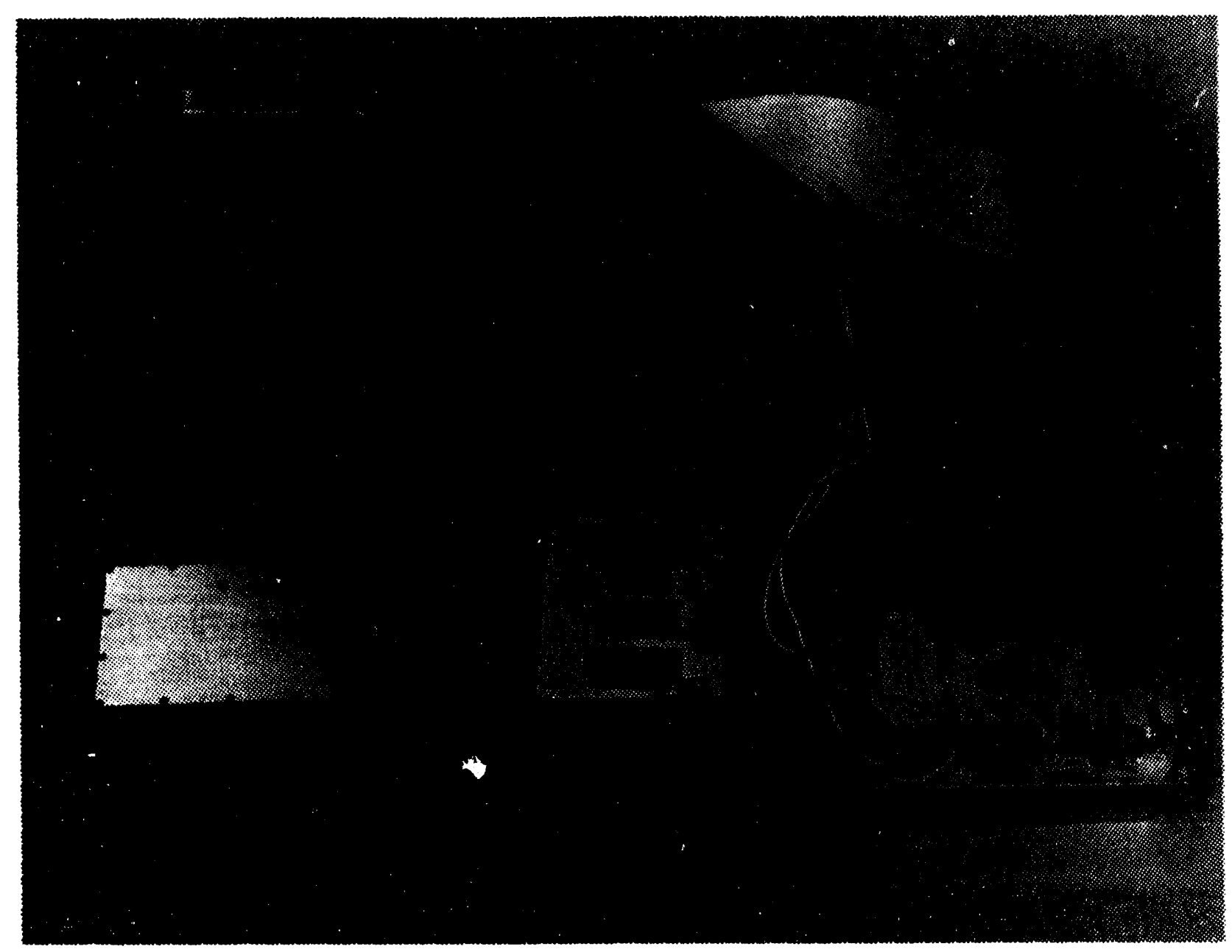

Figure A-21. Photograph of the MISS bus communication breadboard. 


\title{
Appendix B. Power Amplifier Test Data
}

\author{
LCF ENTERPRISES \\ RF Power Amplifiers \\ 621 Barrington Court \\ Newbury Park, CA $91320-5117$
}

(805) 388-8454

Test Data

A020 Serial No. 02A

$\mathrm{V}_{\mathrm{d}}: 28 \mathrm{~V}$ maximum power-supply voltage

$\mathrm{V}_{\mathrm{g}}: 15.0 \mathrm{~V}$ MAXIMUM GATE VOLTAGE

$\mathrm{I}_{\mathrm{dq}}: 100 \mathrm{~mA}$ per side stage 1

0.2 A per side stage 2

0.2 A per side stage 3

Temperature: $25 \infty \mathrm{C}$

$8 / 29 / 92$

Tested by PFF (with external resistors)

WARNING! WARNING! WARNING! WARNING! WARNING! WARNING!

This is a high-performance unit in a very small package. Please read the included application note on high performance, open-architecture amplifiers. If you have any questions, please contact LCF technical support.

Maximum recommended RF input drive: $17 \mathrm{dBm}(50.12 \mathrm{~mW})$

Maximum recommended RF output: $50.21 \mathrm{dBm}$ (105 W) INTO 50 OHM NOMINAL LOAD

Maximum recommended drain current: 5.0 A per side

HEAT SINK REQUIRED. USE THERMAL COMPOUND.

MAXIMUM RECOMMENDED CASE TEMPERATURE FOR FULL RATED OUTPUT POWER IS $60 \infty \mathrm{C}$.

RECOMMEND USING TWO SEPARATE FAST BLOW FUSES OF 5.0 AMP PER SIDE FOR INITIAL TURN ON AND SET UP.

BE CAREFUL NOT TO EXCEED THE MAXIMUM OUTPUT POWER DUE TO GAIN VARIATION ACROSS THE BAND. AN INPUT DRIVE LEVEL CORRESPONDING TO THE RATED OUTPUT POWER AT THE LOWER GAIN PORTIONS OF THE BAND WILL OVERDRIVE THE AMPLIFIER IN THE HIGHER GAIN PORTIONS OF THE BAND. 
THE POWER RATING APPLIES TO A 50-OHM NOMINAL LOAD. DO NOT DRIVE FULL POWER INTO A BAD MISMATCH.

Note: Power-supply surges can result from abrupt cganges in load current. DO NOT PULSE FULL RF INPUT DRIVE OFF TO AVOID AMPLIFIER BURNOUT. That is, many power supplies cannot respond to a current change of approximately $10 \mathrm{~A}$ through the lead inductance in a few microseconds, and pulsing the RF drive off abruptly can deliver a large voltage spike at the amplifier depending on the power supply connection. Either adjust RF input drive up and down gradually, or turn off power supply before abruptly turning full RF input drive off. A large electrolytic capacitor connected directly to the amplifier output stage power supply feedthru will help filter power supply surges.

Note: Low-frequency feedback between stages through the poer supply connection can generate low-frequency oscillations in the power supply lines which can develop breakdown voltage on the transistors. ENSURE THERE IS GOOD LOW-FREQUENCY ISOLATION AND DECOUPLING IN THE POWER SUPPLY CONNECTION BETWEEN THE STAGES TO AVOID AMPLIFIER BURNOUT. 
Table B-1. Specifications for nimiature synthesized exciter/transmitter

\begin{tabular}{|c|c|c|c|c|c|c|}
\hline Freq & $\begin{array}{l}\text { Output } \\
\text { Power }\end{array}$ & $\begin{array}{c}\text { Drain } \\
\text { Voltage }\end{array}$ & $\begin{array}{l}\text { Drain } \\
\text { Current }\end{array}$ & $\begin{array}{l}\text { DC } \\
\text { Power }\end{array}$ & Eff & Gain \\
\hline $400 \mathrm{MHz}$ & $101.1 \mathrm{~W}$ & $28.37 \mathrm{~V}$ & $\begin{array}{l}\text { I1 } 4.35 \mathrm{~A} \\
\text { I2 } \\
4.27 \mathrm{~A}\end{array}$ & $244.6 \mathrm{~W}$ & $41.3 \%$ & $\begin{array}{c}37.5 \mathrm{~dB} \\
(+12.5 \mathrm{dBm} \mathrm{in})^{* *}\end{array}$ \\
\hline $380 \mathrm{MHz}$ & $100.9 \mathrm{~W}$ & $28.49 \mathrm{~V}$ & $\begin{array}{l}\text { I1 } 4.21 \mathrm{~A} \\
\text { I2 } 4.07 \mathrm{~A}\end{array}$ & $235.9 \mathrm{~W}$ & $42.8 \%$ & $\begin{array}{c}35.0 \mathrm{~dB} \\
(+15.0 \mathrm{dBm} \text { in })\end{array}$ \\
\hline $360 \mathrm{MHz}$ & $100.1 \mathrm{~W}$ & $28.59 \mathrm{~V}$ & $\begin{array}{l}\text { I1 } 4.71 \mathrm{~A} \\
\text { I2 } \\
4.48 \mathrm{~A}\end{array}$ & $262.7 \mathrm{~W}$ & $38.1 \%$ & $\begin{array}{c}33.5 \mathrm{db} \\
(+16.5 \mathrm{dBm} \text { in })\end{array}$ \\
\hline $340 \mathrm{MHz}$ & $101.0 \mathrm{~W}$ & $28.70 \mathrm{~V}$ & $\begin{array}{ll}\text { I1 } & 4.42 \mathrm{~A} \\
\text { I2 } & 4.45 \mathrm{~A}\end{array}$ & $254.6 \mathrm{~W}$ & $39.7 \%$ & $\begin{array}{c}34.8 \mathrm{~dB} \\
(+15.2 \mathrm{dBm} \text { in })\end{array}$ \\
\hline $320 \mathrm{MHz}$ & $101.5 \mathrm{~W}$ & $28.79 \mathrm{~V}$ & 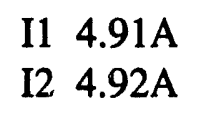 & $283.0 \mathrm{~W}$ & $35.9 \%$ & $\begin{array}{c}35.0 \mathrm{db} \\
(+15.1 \mathrm{dBm} \text { in })\end{array}$ \\
\hline $300 \mathrm{MHz}$ & $100.7 \mathrm{~W}$ & $27.79 \mathrm{~V}$ & 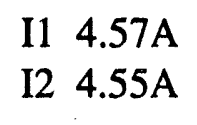 & $253.4 \mathrm{~W}$ & $39.7 \%$ & $\begin{array}{c}36.5 \mathrm{~dB} \\
(+13.5 \mathrm{dBm} \text { in })\end{array}$ \\
\hline $280 \mathrm{MHz}$ & $101.7 \mathrm{~W}$ & $27.85 \mathrm{~V}$ & $\begin{array}{ll}\text { I1 } & 4.54 \mathrm{~A} \\
\text { I2 } & 4.52 \mathrm{~A}\end{array}$ & $252.3 \mathrm{~W}$ & $40.3 \%$ & $\begin{array}{c}37.5 \mathrm{~dB} \\
(+12.6 \mathrm{dBm} \text { in })\end{array}$ \\
\hline $260 \mathrm{MHz}$ & $101.8 \mathrm{~W}$ & $27.93 \mathrm{~V}$ & $\begin{array}{ll}\text { I1 } & 4.39 \mathrm{~A} \\
\text { I2 } & 4.38 \mathrm{~A}\end{array}$ & $245.0 \mathrm{~W}$ & $41.6 \%$ & $\begin{array}{c}39.1 \mathrm{~dB} \\
(+11.0 \mathrm{dBm} \text { in })\end{array}$ \\
\hline $240 \mathrm{MHz}$ & $102.5 \mathrm{~W}$ & $28.08 \mathrm{~V}$ & $\begin{array}{ll}\text { I1 } & 4.14 \mathrm{~A} \\
\text { I2 } & 4.15 \mathrm{~A}\end{array}$ & $232.8 \mathrm{~W}$ & $44.0 \%$ & $\begin{array}{c}39.2 \mathrm{~dB} \\
(+10.9 \mathrm{dBm} \text { in })\end{array}$ \\
\hline $220 \mathrm{MHz}$ & $103.0 \mathrm{~W}$ & $28.17 \mathrm{~V}$ & $\begin{array}{ll}\text { I1 } & 3.97 \mathrm{~A} \\
\text { I2 } & 4.05 \mathrm{~A}\end{array}$ & $225.9 \mathrm{~W}$ & $45.6 \%$ & $\begin{array}{c}38.1 \mathrm{~dB} \\
(+12 \mathrm{dBm} \text { in })\end{array}$ \\
\hline
\end{tabular}

${ }_{32}^{* *}$ Input power level 
$r$
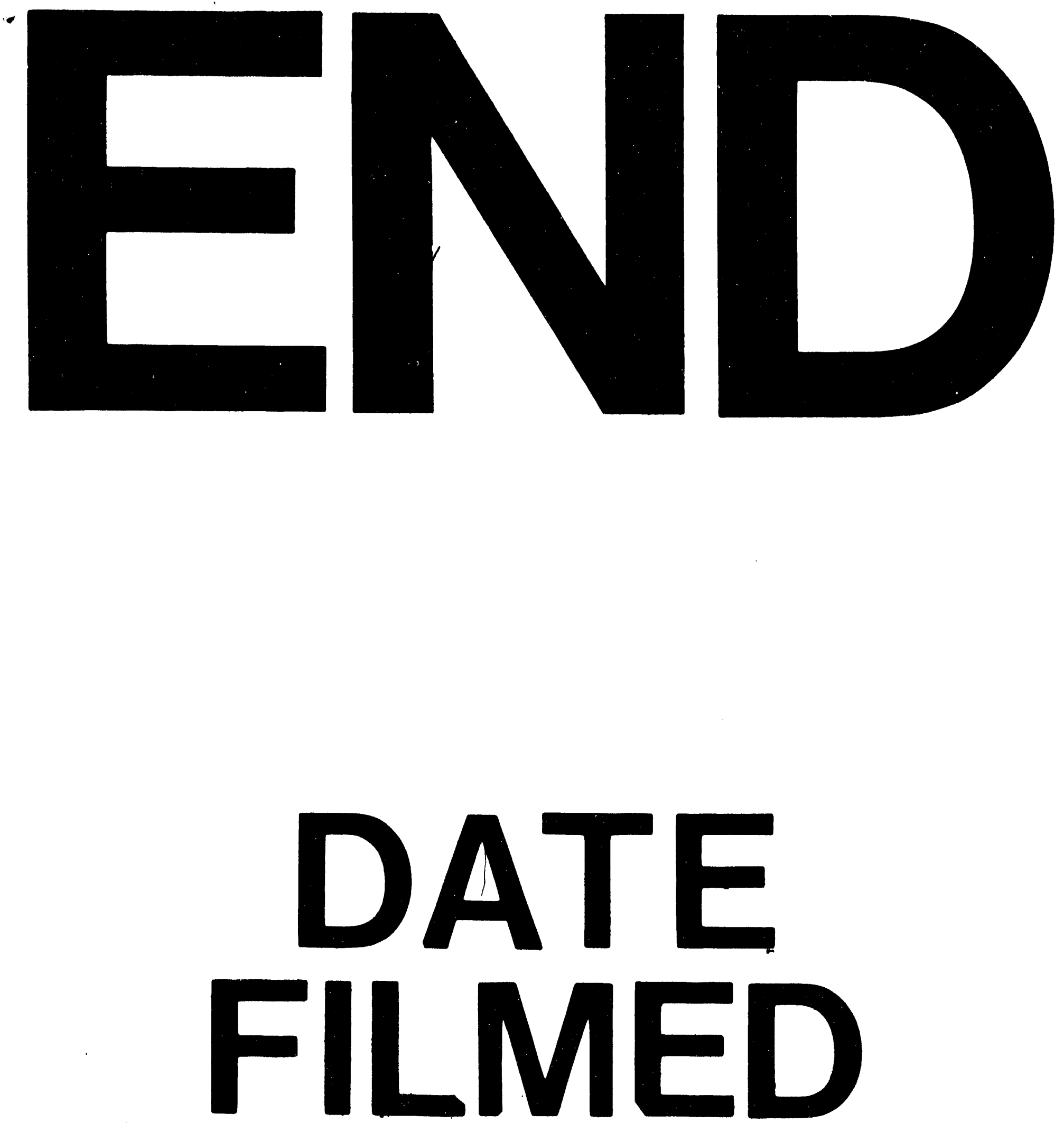

1

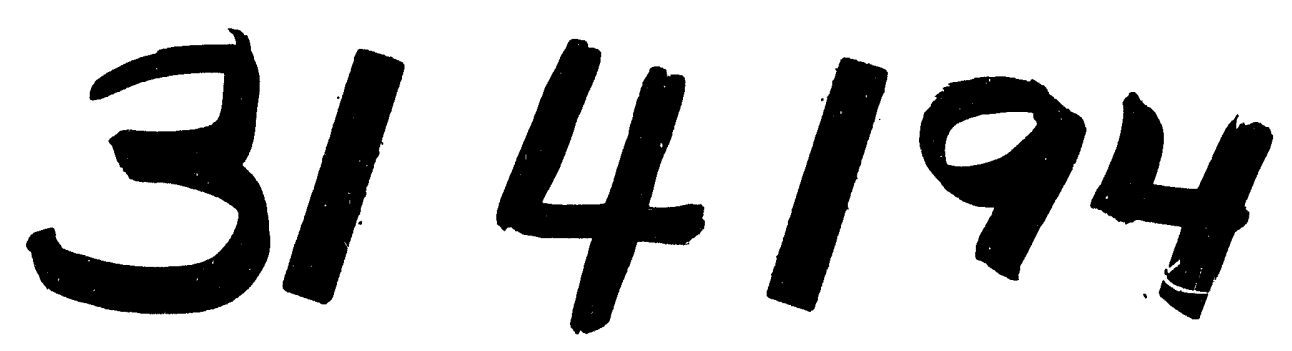


